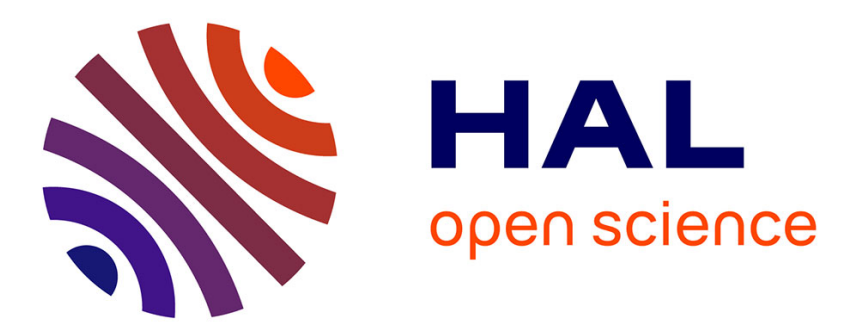

\title{
The protein expression landscape of mitosis and meiosis in diploid budding yeast
}

Emmanuelle Becker, Emmanuelle Com, Régis Lavigne, Marie-Hélène Guilleux, Bertrand Evrard, Charles Pineau, M. Primig

\section{- To cite this version:}

Emmanuelle Becker, Emmanuelle Com, Régis Lavigne, Marie-Hélène Guilleux, Bertrand Evrard, et al.. The protein expression landscape of mitosis and meiosis in diploid budding yeast. Journal of Proteomics, 2017, 156, pp.5-19. 10.1016/j.jprot.2016.12.016 . hal-01485858

HAL Id: hal-01485858

https://hal-univ-rennes1.archives-ouvertes.fr/hal-01485858

Submitted on 1 Jun 2017

HAL is a multi-disciplinary open access archive for the deposit and dissemination of scientific research documents, whether they are published or not. The documents may come from teaching and research institutions in France or abroad, or from public or private research centers.
L'archive ouverte pluridisciplinaire HAL, est destinée au dépôt et à la diffusion de documents scientifiques de niveau recherche, publiés ou non, émanant des établissements d'enseignement et de recherche français ou étrangers, des laboratoires publics ou privés. 


\section{The protein expression landscape of mitosis and meiosis in diploid budding}

\section{yeast}

Emmanuelle Becker ${ }^{1}$, Emmanuelle Com $^{1,2}$, Régis Lavigne ${ }^{1,2}$, Marie-Hélène Guilleux ${ }^{1,3}$, Bertrand Evrard $^{1}$, Charles Pineau ${ }^{1,2}$, and Michael Primig ${ }^{1, *}$

${ }^{1}$ Inserm U1085 IRSET, Université de Rennes 1, 35042 Rennes, France

${ }^{2}$ Protim, Université de Rennes 1, 35042 Rennes, France

${ }^{3}$ Present address: University Hospital Rennes, 35000 Rennes, France

*Corresponding author: michael.primig@inserm.fr

Short title: Budding yeast proteome of mitosis versus meiosis

Key words: Proteome, transcriptome, respiration, sporulation, meiosis, long noncoding RNAs, double stranded RNAs, budding yeast 


\begin{abstract}
Saccharomyces cerevisiae is an established model organism for the molecular analysis of fundamental biological processes. The genomes of numerous strains have been sequenced, and the transcriptome and proteome of major phases during the haploid and diploid yeast life cycle have been determined. However, much less is known about dynamic changes of the proteome when cells switch from mitotic growth to meiotic development. We report a quantitative protein profiling analysis of yeast cell division and differentiation based on mass spectrometry. Information about protein levels was integrated with strand-specific tiling array expression data. We identified a total of 2366 proteins in at least one condition, including 175 proteins showing a statistically significant $\geq 5$-fold change across the sample set, and 136 proteins detectable in sporulating but not respiring cells. We correlate protein expression patterns with biological processes and molecular function by Gene Ontology term enrichment, chemoprofiling, transcription interference and the formation of double stranded RNAs by overlapping sense/antisense transcripts. Our work provides initial quantitative insight into protein expression in diploid respiring and differentiating yeast cells. Critically, it associates developmentally regulated induction of antisense long noncoding RNAs and double stranded RNAs with fluctuating protein concentrations during growth and development.
\end{abstract}




\section{Introduction}

The budding yeast $S$. cerevisiae is a model organism widely used to study important biological processes. Yeast genes are exceptionally well defined, since a large number of genomes from different strain backgrounds have been sequenced [1]. The transcriptome and proteome in important phases of yeast's haploid and diploid life cycle were analysed, which revealed complex and often uncorrelated mRNA/protein expression patterns [2-11]. These profiling data were complemented by a variety of functional genomics studies that yielded insight into the roles of nearly all currently known protein-coding genes during mitotic growth, stress response, gametogenesis (sporulation) and spore germination [12-16].

The meiotic process is induced by nutritional cues mediated by protein kinase A (PKA) and target of rapamycin complex 1 (TORC1) signalling, and leads to the formation of four haploid spores in an ascus [17-19]. Only a few analyses of the meiotic yeast proteome have been carried out so far, and all but one are based on protein separation by two-dimensional gel electrophoresis [20-23]. Early work attributed global down-regulation of the meiotic proteome mostly to proteolysis, but more recently it was found that protein translation controlled via extended developmental stage-specific 5'-untranslated regions (5'-UTRs) plays an important and perhaps widespread role during gametogenesis [24-29]. Additional mechanisms affecting cellular protein concentrations involve long non-coding RNAs (lncRNAs) such as stable unannotated transcripts (SUTs) [30, 31]; reviewed in [32-34]. Interestingly, meiotic cells strongly accumulate numerous lncRNAs, including many that partially or completely overlap sense mRNAs $[35,36]$. Such sense/antisense transcript pairs contribute to the control of proteins and lncRNAs in vegetatively growing cells, since overlapping sense/antisense mRNAs that form double-stranded RNAs (dsRNAs) in vivo can influence protein levels during mitotic growth [37]. Moreover, antisense regulatory lncRNAs, such as Xrn1-sensitive unstable transcripts (XUTs), are protected against nonsense mediated decay when they are engaged in dsRNA structures with sense transcripts in vegetative cells [38].

Quantitative insight into the meiotic proteome is critical for a better understanding of how the transcriptome controls the proteome during the process. Various high-throughput methods to precisely determine protein abundance in yeast have been developed, such as SILAC (Stable Isotope Labelling by Amino acids in cell Culture) [4], SWATH (Sequential Windowed 
Acquisition of all THeoretical fragment-ion spectra) [39], and T3PQ (Top 3 Protein Quantification) [40, 41].

In this study, we carried out T3PQ-based quantitative protein profiling of diploid yeast cells in mitosis and meiosis and integrated the output with corresponding tiling array expression data. Our results reveal insight into the complex expression patterns within the dynamic proteome of mitosis, meiosis and gametogenesis in a simple eukaryote, and point to a possible link between antisense lncRNA expression, dsRNA formation and developmental stage specific changes in protein levels.

\section{Materials and Methods}

Strains and media

Diploid SK1 MATa/ $\alpha$ cells were cultured in rich medium (YPD), pre-sporulation medium (YPA) and sporulation medium (SPII) as published [9].

\section{Detection of meiotic landmark events}

Pre-meiotic DNA replication was analysed using fluorescence activated cell sorting (FACS) and transition through meiotic M-phase was monitored by staining the cells with DAPI and scoring the formation of bi- and tetranucleate cells as published [9].

\section{Protein preparation for mass spectrometry}

Fermenting cells undergoing mitotic growth (YPA) and meiotic cells at two time points (SPII $6 \mathrm{~h}$ and $8 \mathrm{~h}$ ) were harvested and frozen using liquid nitrogen prior to storage at $-80^{\circ} \mathrm{C}$. Total protein extracts were prepared using a tandem buffer system for soluble and membrane bound proteins and fractionated into 30 trypsin-digested samples via SDS-PAGE gel electrophoresis as described $[10,11]$.

\section{Protein identification and quantification}

Digested peptides were analysed using a LTQ-OrbiTrap XL mass spectrometer (ThermoFisher Scientific). The instrument was operated in its data-dependent mode by automatically switching between full survey scan MS and consecutive MS/MS acquisition. Survey full scan MS spectra (mass range 400-2000) were acquired in the OrbiTrap section of the instrument with a resolution of $r=60,000$ at $\mathrm{m} / \mathrm{z} 400$; ion injection times are calculated for each spectrum to allow for accumulation of $10^{6}$ ions in the OrbiTrap. The ten most intense 
peptide ions in each survey scan with an intensity above 2000 were sequentially isolated and fragmented in the linear ion trap by collision-induced dissociation. For OrbiTrap measurements, an external calibration was used before each injection series ensuring an overall error mass accuracy below $5 \mathrm{ppm}$ for the detected peptides. MS data were saved in RAW file format (Thermo Fisher Scientific) using XCalibur 2.0.7 with tune 2.4. We performed the data analysis using Proteome Discoverer 1.2 software supported by Mascot (Mascot server v2.2.07; www.matrixscience.com) and SEQUEST database search engines. We identified proteins by querying the Saccharomyces Genome Database (release 06/01/2010; 6717 amino acid sequences) using a mass tolerance for MS of $10 \mathrm{ppm}$ and for MS/MS of 0.5 Dalton. We selected trypsin allowing for one miss cleavage. Fixed and variable modifications were carbamidomethylation of cysteines and oxidation of methionine, respectively. We filtered identified peptides based on Xcorr values and the Mascot score to obtain a false discovery rate (FDR) of $1 \%$ at the peptide level, using the Mascot decoy search strategy, which corresponds to an average FDR of 5\%. We quantified protein levels using the Precursor Ion Area Detector method implemented in the Proteome Discoverer Software. This approach calculates the Protein Abundance Index (PAI) of each protein by averaging the intensity of the three strongest signal peaks for peptides, according to the TOP3 method [40]. For each sample, we $\log 2$ transformed the PAI and normalized the data using the quantilequantile method.

\section{Minimal Information About a Proteome Experiment (MIAPE) compliance}

The raw mass spectrometry proteomics data were uploaded to the ProteomeXchange Consortium and are available at the PRIDE partner repository via the identification number PXD001275 [42].

\section{Selection of proteins showing significantly different levels in mitosis and meiosis}

2366 proteins were identified at least once in at least one sample. We focused on the 582 proteins reproducibly identified in all three conditions. After quantile-quantile normalization, we selected proteins with an estimated abundance of $\log 2(\mathrm{x})>23.759$ (corresponding to the $25^{\text {th }}$ quantile) in at least one experiment (564/582), and identified those among them that showed a $\geq 5$-fold change in at least one pair of conditions (245/564). 175/245 proteins passed a statistical t-test with a linear fitting of the variance (Limma R package) and a false discovery rate (FDR) set at 5\% [43, 44]. We empirically determined that $\mathrm{K}$-means clustering at $\mathrm{K}=5$ generated a useful number of expression patterns (Cluster1-5) within our sample set [45, 46]. 


\section{Selection of proteins specifically identified in sporulation medium}

Among 2366 proteins we identified 136 that were not detected in duplicate samples of cells cultured in pre-sporulation medium (YPA), but present in duplicate samples from cells cultured in SPII at $6 \mathrm{~h}$ or $8 \mathrm{~h}$ or both, with an estimated abundance $\log 2(\mathrm{x})>23.759\left(25^{\text {th }}\right.$ quantile) in at least one sample. The proteins were grouped into four meiosis-specific clusters based on their patterns: ms cluster $1(\mathrm{n}=33)$ includes proteins peaking at SPII $6 \mathrm{~h}$ (fold-change $>2.5$ between $6 \mathrm{~h}$ and $8 \mathrm{~h})$; ms cluster $2(\mathrm{n}=28)$ includes proteins highly expressed at $6 \mathrm{~h}$ and $8 \mathrm{~h}$ (abundance $\log 2(x)>24.85$, corresponding to the $50^{\text {th }}$ quantile); ms cluster $3(n=46)$ includes proteins with a medium abundance at both SPII $6 \mathrm{~h}$ and $8 \mathrm{~h}$; ms cluster $4(\mathrm{n}=29)$ includes proteins with a maximal abundance at $8 \mathrm{~h}$ (fold-change $>2.5$ between SPII $8 \mathrm{~h}$ and $6 \mathrm{~h}$ ).

\section{Selection of proteins encoded by genes paired with overlapping antisense IncRNAs}

Among 100 known overlapping sense/antisense mRNA/lncRNA pairs [36], we selected 26 cases where the mRNA encodes a protein we identified in at least one experimental condition, and integrated protein profiling data with tiling array expression data for both DNA strands (Supplemental Table S2).

\section{Functional analysis of protein clusters}

We determined significant enrichment of Gene Ontology Biological Process terms [47] in protein clusters employing GOToolBox [48], using a hypergeometric law corrected for multiple testing with Benjamini and Hochberg correction, with a FDR set to 1\% [49].

\section{Integration of Sc_tiling array expression profiling data}

Microarray expression data were described in [36]. The full tiling array dataset is available for viewing via the Saccharomyces Genomics Viewer (SGV, sgv.genouest.org; [50]) and the ReproGenomics Viewer (RGV, rgv.genouest.org; [51]). This dataset covers the expression of the yeast genome (SK1 strain), in rich medium (YPD), acetate medium (YPA), and during sporulation (SPII, hourly samples from 1h to 10h). It was generated in 2009 using Sc_tlg array data based on sacCer2 and was converted with the LiftOver tool (UCSC) to be consistent with the current sacCer3 annotation. The colour scale used in the figure is directly extracted from the dataset. For each protein, we (i) identified the exact transcript coordinates from the Saccharomyces Genome Database (SGD, sacCer3) [52]; then (ii) identified tiling array segments overlapping or included in this region; and finally, (iii) computed a weighted mean of these values, whereby each segment contributed to the mean proportionally to the 
percentage of the region it represented. Finally, we computed the same weighted mean for the antisense transcript using the same coordinates on the opposite DNA strand. The complete output together with functional annotation (retrieved from SGD on April 28 $8^{\text {th }} 2014$ ) is searchable in Supplemental Table S1.

\section{Integration of functional chemoprofiling data}

Results of the Yeast Fitness Database (http://fitdb.stanford.edu/) are integrated and presented in Supplemental Table S1. The table indicates if a homozygous deletion mutant lacking a given gene shows an increased sensitivity toward at least one of 145 chemicals. Specifically, we used the data from supplemental file hom.z_tdist_pval_nm.counts.smallmol.cutoff.01.tab [16].

\section{Interpretation of RNA-Sequencing and ribosome profiling data}

Compressed data files from [28] were downloaded from the NCBI's GEO repository [53] and imported into the Integrated Genomics Viewer (IGV version 2.3.66) [54]. We used the "S. cerevisiae sk1" genome annotation file. For clarity, the original files were renamed to reflect mitosis and progression through the meiotic pathway.

\section{Interpretation of dsRNA profiling data}

Information about dsRNAs formed in wild-type cells (WT) or a temperature sensitive xrnl mutant ( $x r n l)$ strain was compared to isogenic strains expressing fungal Dicer and Argonaut orthologs (RNAi, xrn1 RNAi). The data are available via http://vm-gb.curie.fr/mw2/ (Genome-wide mapping of double-stranded RNA), [38].

\section{Identification of genes conserved between yeast and human}

A comprehensive list of yeast genes for which human orthologs or homologs have been identified was provided by the Saccharomyces Genome Database (as of May 2016; SGD, www.yeastgenome.org) [52]. 


\section{Results}

\section{Experimental design and rationale}

In previous work, we used Direct Iterative Protein Profiling (DIPP) to determine the proteome of rapidly dividing diploid SK1 MATa/ $\alpha$ yeast cells cultured in rich medium (YPD), and respiring cells cultured in rich medium with acetate as the sole carbon source (YPA), which is often used as pre-sporulation medium $[10,11]$. Here, we compared the proteomes in dividing versus differentiating yeast cells using acetate as a carbon source, by analysing samples cultured in YPA (mitosis) and SPII at $6 \mathrm{~h}$ and $8 \mathrm{~h}$ (broadly corresponding to meiosis I and II) with the quantitative label-free T3PQ method. We made this choice because profound physiological changes during gametogenesis may interfere with quantitative proteomics methods that require uptake of compounds, such as SILAC. Moreover, T3PQ was found to be more reproducible, linear and robust than other label-free approaches [41].

Information on protein abundance was combined with published DNA strand specific tiling array expression signals [36], and interpreted using data from RNA-Sequencing/ribosome footprinting [28], dsRNA profiling [38] and chemoprofiling [16] experiments. We focussed on two classes of proteins: the first showed changing abundance within the sample set and the second was detected only in meiotic cells. This enabled us to interpret protein detection patterns in the context of (i) protein function, (ii) expression of overlapping sense/antisense transcripts, and (iii) dsRNA formation (Figure 1A, B).

\section{Protein profiling of mitosis versus meiosis}

Duplicate samples from each time point were pre-fractionated using one-dimensional SDS gel electrophoresis and processed as previously published (Figure S1A) [10]. A total of 2366 proteins were identified by mass spectrometry in at least one duplicate of samples from cells cultured in YPA, SPII $6 \mathrm{~h}$ or SPII 8h, and quantified using the label-free T3PQ method (Table 1). The distribution of protein abundance, which is calculated as the mean of the three strongest signals measured for peptides from each protein identified, was sufficiently similar across the sample set (Figure S1B). As expected, we detected more proteins in mitotically dividing cells (1242 in both YPA duplicates, 402 only in YPA1 and 201 only in YPA2;) than in cells entering meiotic M-phase (958 in both SPII 6h duplicates, 364 in SPII 6h1 and 202 in SPII 6h2), and cells entering post-meiotic spore formation (729 in both SPII $8 \mathrm{~h}$ duplicates, 470 in SPII 8h1 and 115 in SPII 8h2; Figure 1C). 
Among the total output we detected 973 proteins in all time points at least once, 202 in YPA and SPII6h, 67 in YPA and SPII8h and 163 in SPII 6h and 8h. Finally, 603, 186 and 111 were found only in YPA, SPII6h or SPII8h, respectively (Figure 1D, see Figure S1C for the complete set of detection patterns in all samples).

The yield of the T3PQ profiling method was lower than the one obtained with DIPP, because quantifying protein levels precludes multiple rounds of injection (thus decreasing the sensitivity of the approach) and requires more stringent detection criteria [10]; see methods for details. However, our approach identified, technical limitations notwithstanding, a substantial sample of the yeast proteome in dividing and differentiating cells.

\section{Protein peak expression and function correlate during growth and development}

We first sought to explore the mRNA/protein profiles, sense/antisense patterns, and cellular functions of proteins displaying fluctuating levels across out sample set. To this end, we focussed on a subset of 175 proteins (among a total of 2366) for which we obtained signals in all six samples (duplicates in YPA, SPII6h and 8h), whereby signal intensities for at least one sample were above the $25^{\text {th }}$ quantile ( $\left.\log 223.759\right)$, the fold-change between two conditions was $\geq 5$, and the difference was statistically significant (Limma's package t-test, FDR 0.05). To exemplify sense/antisense expression we focus this analysis on protein-coding genes paired with known IncRNAs (Cryptic Unstable Transcripts, CUTs; Stable Unannotated Transcripts, SUTs; Meiotic Unannotated Transcripts, MUTs; Xrn1-sensitive unstable Transcripts, XUTs).

Using Silhouette plots to assess the clusters, we grouped the proteins according to five patterns and ordered them over initial peak levels. 36 proteins in Cluster 1 peak in YPA. mRNA/protein signal intensities in mitosis and meiosis broadly correspond to each other for the majority of them (Figure 2A). However, we also observed cases of increasing, persistent or moderately declining mRNA levels in combination with strongly declining protein concentrations (for example Ent2, Efb1, Met6, Nsr1, Pat1, Rpl30, Rps2, Sdh2, Tif2, Yef3). This likely points in some cases to regulatory mechanisms that act via protein stability during growth and development. We observe meiotic induction of a known antisense lncRNA for RPL5/SUT2589 and RPS13/MUT262 in combination with decreasing mRNA and/or protein levels. Four proteins in this cluster are poorly characterized (Ycl042w, Yfr016c, Ykr018c, Ypl260w); Ycl042w and Ykr018c may be important for protein translation since they 
physically interact with $\mathrm{Sbp} 1$, a translational repressor that binds 5'-untranslated regions of mRNAs [55]. The decreasing levels of Yfr016c and Ypl260w are consistent with a role in chemical stress response not directly related to meiosis-specific landmark events [16]. Gene Ontology (GO) term analysis revealed two major biological processes as being significantly enriched: gene expression ( $p$-value $3.20 \times 10^{-3}$ ) and protein synthesis (translation, $1.91 \times 10^{-7}$; regulation of translation, $7.04 \times 10^{-3}$; and ribosomal subunit assembly, $1.55 \times 10^{-5}$ ) (Figure 2B).

Cluster 2 contains 73 proteins that also peak in mitotic cells but show a slightly extended pattern of expression in meiosis (Figure 2C). mRNA/protein abundance typically correlates well, with some notable exceptions where proteins strongly decline in meiosis in spite of continued or only moderately declining mRNA expression (such as Cpr1, Idh1, Idp2, Lsc1, Lsc2, Pdb1, Rpl28, Ymr099c). We observe meiotic sense/antisense expression for FBP1/SUT281, HOR2/SUT1395, PDC6/MUT645, and RPL35B/SUT1105. In all cases except Fbp1 this phenomenon is associated with decreasing protein levels in sporulating cells. The poorly characterized protein Ymr099c likely encodes a protein involved in carbohydrate metabolism [56]. GO term enrichment identified carbon metabolism (gluconeogenesis, $2.20 \mathrm{x}$ $10^{-9}$; alcohol biosynthetic process, $1.03 \times 10^{-13}$ ), and again protein synthesis (translation; 1.91 $\mathrm{x} 10^{-19}$ ) as key processes in this cluster (Figure 2D).

Cluster 3 comprises 32 proteins that tend to peak at the onset of meiotic M-phase (SPII $6 \mathrm{~h}$ ), whereby only very few cases show strongly deviating mRNA patterns (Ale1, Crc1, Pho86, Yet3). Ato3's decline in concentration is associated with the meiotic induction of an as yet unknown antisense transcript. Mic10/Ycl057c-a is a component of the MICOS complex that was recently shown to be critically involved in mitochondrial architecture [57]. Ypr010c-a is likely also involved in mitochondrial functions because it interacts with Mic60 (subunit of MICOS) and Cor1 (component of the mitochondrial inner membrane electron transport chain) $[58,59]$. Enriched GO terms correspond to the metabolic state of cells in media containing acetate (cellular respiration, $7.08 \times 10^{-3}$ ) and the physiological and architectural changes that accompany spore formation (transport, $4.56 \times 10^{-7}$; phospholipid biosynthetic process, $4.49 \mathrm{x}$ $10^{-3}$ ) (Figure 3B). We note that $19 / 32$ proteins in this cluster are involved in transport, including 11 that pay roles more specifically in intracellular transport.

Cluster 4 contains 26 proteins that peak during meiotic M-phase (SPII $6 \mathrm{~h}$ and $8 \mathrm{~h}$ ) and show similar mRNA/protein patterns, except in the cases of Cdc10, Doa1, Fth1 and Vps75 (Figure $3 \mathrm{C})$. The protein expression patterns we find are consistent with known meiotic and post- 
meiotic roles of Glc7 [60], Mlh2 [61], Prc1, Pep4 [25], and Rim4 [24]. Ydr415 is likely important for protein degradation during meiosis and gametogenesis because it binds Bre5 (ubiquitin protease cofactor) and Ubal (ubiquitin activating enzyme 1) [62]. Enriched GO terms reflect increasing protein turnover during gametogenesis (proteolysis, $1.52 \times 10^{-4}$; vacuolar protein catabolic process, $3.37 \times 10^{-7}$ ), and the response to an environmental signal (cellular response to stress, $3.47 \times 10^{-3}$ ) together with cell development (cell differentiation, $8.80 \times 10^{-4}$; sporulation, $4.52 \times 10^{-4}$ ) (Figure 3D).

We find peak expression at $8 \mathrm{~h}$ in sporulation medium for only 6 proteins and their mRNAs in Cluster 5 (Cis3, Cwp1, Hsp150, Leu2, Rpn13, Yj1160c). The remaining two cases, Pir1 and Pir3 show increasing concentrations in the meiotic samples, while their mRNAs decline (Figure 3E). PIRI/SUT227 shows antagonistic sense/antisense mRNA/lncRNA expression but no concomitant decline of the protein level. HSP150 and LEU2 are associated with antisense transcript expression that decreases when cells switch from respiration to sporulation, while protein concentrations increase. Cwp1 and Pir5/Yjil160c are known be involved in sporulation [14, 63]. Enriched GO terms are consistent with architectural changes during gametogenesis (cell wall organisation, $1.87 \times 10^{-6}$; external encapsulating structure, $1.87 \mathrm{x}$ $10^{-6}$; ascospore-type prospore membrane, $1.00 \times 10^{-2}$ ) (Figure $3 \mathrm{~F}$ ).

Proteins present in meiotic M-phase are important for metabolic functions, signalling, cell architecture and gametogenesis

To gain further insight into the roles of proteins undetectable in respiring cells but present during sporulation, we identified 136 proteins not found in YPA but significantly detected in SPII ( $6 \mathrm{~h}$ and/or $8 \mathrm{~h}$; signal values $>25^{\text {th }}$ percentile, Figure S3), and grouped them into four meiosis-specific clusters (msClusters) according to their peak levels. We expected this approach to identify (i) proteins involved in meiosis and gametogenesis, (ii) cell cycle regulated proteins, which are below the threshold level of detection in asynchronous mitotic cells but not semi-synchronous meiotic cells, or (iii) stress response proteins that are undetectable during respiratory growth under perfect conditions (well oxygenated medium at $30^{\circ} \mathrm{C}$ ) but present during sporulation.

msCluster 1 contains proteins that peak at the onset of meiotic M-phase (SPII 6h). Among 33 proteins in msCluster 1, 27 show uncoupled mRNA/protein levels, that is to say, the mRNA accumulates in mitosis although the protein is detected only in meiosis (Figure 4A); this 
phenomenon holds true for the vast majority of the proteins in msClusters 1-4. To the contrary, the mRNAs encoding the remaining six proteins are undetectable or barely above background in mitosis and therefore correspond to the protein pattern we observe: Dtr1 (spore wall synthesis, [64]), Fks3 (spore wall assembly, [65]), Ime2 (regulator of meiotic progression, reviewed in [66]), Tep1 (spore wall formation, [67]), Lds2/Yol047c (spore wall assembly, [68]), and Ypr078c (stress response, [69]). It is noteworthy that all of them, except Ypr078c, are directly involved in meiosis and gamete formation. Examples for antisense IncRNA expression antagonistic with protein levels in mitosis and meiosis are YOL047C/SUT357, RRT8/MUT1398 and YLR050C/SUT253. Five poorly characterized proteins are likely involved in ion transport $(\mathrm{Zsp} 1 / \mathrm{Ybr} 287 \mathrm{w})$, lipid metabolism (Mpo1/Ygl010w), cell wall integrity signalling (Dck1/Ylr422w), chemical stress response (Ypl014w; [16]), and DNA metabolism or genome stability (Ypr078c; see yeastgenome.org). GO term enrichment is consistent with cells progressing through gametogenesis (sporulation, $7.99 \times 10^{-3}$; spore wall assembly, $1.27 \times 10^{-3}$ ) (Figure 4B).

msCluster 2 contains 28 proteins that are highly expressed in both meiotic samples since their signals are above the median in both meiotic samples (SPII 6h and 8h), including 11 that peak at $8 \mathrm{~h}$. Again, for the majority $(23 / 28)$ we find mRNA in mitotic cells, which is consistent with the notion that these transcripts may not be translated during growth or the proteins may be unstable in mitosis (Figure $4 \mathrm{C}$ ). For the remaining five cases we find corresponding mRNA/protein patterns: Cda2 (spore wall assembly, [70]), Dmc1 (meiotic double strand break repair, reviewed in [71]), Lds1/Yal018c (spore wall assembly, [68]), Smk1 (spore wall assembly, [72]), and Spo21 (meiotic modification of the spindle pole body, [73]). We detect antagonistic antisense lncRNA expression for DMC1/SUT521, GDH3/SUT434, and SMK1 (the latter being associated with an unannotated antisense transcript). The poorly characterised proteins Ynl050c and Yhr202w may play roles in meiosis or gametogenesis; we note that the latter binds Rad53 and Srs2, which are involved in DNA repair and meiotic recombination, respectively. Yil077c and Yk1077w are likely involved in nutritional and chemical stress response (see yeastgenome.org); [16]. GO term analysis associates signal transduction (intracellular signalling cascade, $2.50 \times 10^{-4}$ ), energy metabolism (cAMP metabolic process, $3.58 \times 10^{-4}$ ), and gametogenesis (sporulation, $5.40 \times 10^{-4}$ ) for msCluster 2 (Figure 4D).

msCluster 3 contains 46 proteins that are undetectable in YPA and moderately abundant in both meiotic samples (Figure 5A). Protein levels appear to be uncoupled from mRNA in mitosis in all cases apart from Loh1 (spore wall assembly, [68]), Spo19 (spore formation, 
[74]), Ysw1 (pro-spore membrane formation, [75]), and Ypr027c (competitive fitness; binds $\mathrm{Nab} 2$, a protein involved in mRNA transport and processing; [76, 77]. Other proteins in msCluster 3 known to be involved in meiosis and gametogenesis are Bem2 (ascus wall formation; [78]), Clb1 (regulation of meiosis; [79, 80]), and Pms1 (mismatch repair; [81]). Six other poorly characterized proteins may be important for processes relevant for or concomitant to gametogenesis, such as apoptosis (Ybl055c), heavy metal detoxification (Ybr139w), sugar transport (Ybr241c), stress response signal transduction (Egh1/Yir007w), and toxin resistance (Ymr147w, Ypl113c; see yeastgenome.org). GO term enrichment data are in agreement with the meiotic divisions (spindle organisation, $5.58 \times 10^{-3}$ ) and spore formation (ascospore-type prospore, $\left.1.12 \times 10^{-4}\right)$. We also identified cell death $\left(4.26 \times 10^{-3}\right)$, which is potentially relevant for spore quality control and germination [82] (Figure 5B).

msCluster 4 includes 29 proteins that show peak levels at the exit of meiotic M-phase (SPII $8 \mathrm{~h}$ ) (Figure 5C). mRNA/protein patterns are uncoupled for 20 proteins, but appear broadly consistent in nine cases: Gas2 (spore wall assembly, [83]), Rrt5 (rDNA expression, [84]), Spr2/Yor214c (Spo19 paralog, [85]), Spr3 (spore formation, [86]), Spr1 (spore thermoresistance, [87]), Sps2 and Sps22 (spore wall assembly, [88]), Yn1019c (heat stress response, [89]), and Ynl033w (binds Hek2, involved in mRNA processing and telomere maintenance, $[90,91])$.

Three genes in msCluster 4 are associated with antisense lncRNAs for which the expression profile is antagonistic with mRNA/protein levels: SPR1/SUT785, YNL033W/SUT2342, and YNL019C, for which we observe strong expression of an as yet unannotated antisense transcript. Two other uncharacterized proteins in msCluster 4 are possibly involved in DNA damage response (Ybl029c-a), and protein translation (Ymr114c) (yeastgenome.org). GO term enrichment reflects progression through advanced stages of gamete formation (ascospore formation, $5.03 \times 10^{-7}$; spore wall assembly, $4.05 \times 10^{-5}$; sexual reproduction, 6.23 x $10^{-6}$ ) (Figure 5E).

\section{Chemoprofiling reveals global stress response component of the meiotic proteome}

Earlier functional genomics work revealed that most genes expressed in differentiating cells but not vegetatively growing cells are not directly involved in meiosis and gametogenesis [14, $15,92]$. We therefore hypothesized that yeast responds to a specific nutritional cue - lack of nitrogen and a fermentable carbon source - not only by initiating meiosis, but by triggering a 
broad metabolic- and stress response, regardless of otherwise favourable culture conditions including optimal oxygen supply, ideal temperature of $30^{\circ} \mathrm{C}$, neutral $\mathrm{pH}$, and no environmental insult of any kind.

To test this idea, we explored potential functions of our target proteins using chemoprofiling data [16]. We identified among the SPII-specific proteins 63 cases that bear the annotation "function unknown". Apart from six genes important for meiosis and spore formation ( $\mathrm{LOHl}$, MSC7, OSW5, SPS22, SPO71, SPO75), for which deletions tend to display few resistance phenotypes, no direct role in gametogenesis has been annotated in SGD. For mutants lacking any one of the remaining 56 genes we observe a wide variety of increased sensitivities against selected toxins, disease-related drugs, anti-microbial/viral agents and nutritional supplements (Figure 6, see Table S1 for the complete set of phenotypes).

We conclude that among our meiotically induced target proteins, which are undetectable in vegetatively growing cells using acetate as a carbon source, the overwhelming majority is involved in metabolic functions and a wide variety of stress responses. The result confirms and extends earlier findings from RNA- and protein profiling studies that the accumulation of proteins specifically important for meiosis and gametogenesis is inextricably linked to a global transcriptional and translational response, which involves numerous proteins involved in metabolic pathways, signalling, cell architecture, and detoxification [3, 9, 20-22, 93]. This explains why most genes identified as meiosis-specific by microarrays (when compared to growth medium or pre-sporulation medium) are not directly involved in meiotic landmark events such as formation of the synaptonemal complex, recombination, chromosome separation in meiosis I and II and gamete formation.

\section{Induction of antisense transcription can correlate with low protein levels}

It has been reported that antisense transcription of lncRNAs can interfere with the expression of overlapping sense mRNAs [94]; reviewed in [32]. Interestingly, co-expression of overlapping sense/antisense transcripts in the same cell allows, in many but not all cases, for dsRNA formation in vivo during growth and/or development [36-38, 95]. This phenomenon can influence protein levels in E. coli, budding yeast and mammals [37, 38, 95, 96]. Therefore, we further explored our mRNA/protein data in the context of a genome-wide assay detecting dsRNAs formed by sense/antisense pairs, available for viewing at vmgb.curie.fr/mw2/small_RNA-seq; [38]. 
We selected 26 proteins showing variable levels within the samples, and that overlap with an antisense transcript expressed in at least one condition (Table S2). The proteins were organised into five groups depending on their expression patterns. Manual inspection of RNA profiling data revealed that the vast majority of these transcript pairs $(17 / 26,65 \%)$ can form dsRNAs in vivo (Figure 7A) [38]. Nine cases for which no dsRNAs were detected include two genes associated with strongly induced lncRNAs and decreasing protein levels in meiosis (SED4/MUT214, and YMR034C/MUT1155). We therefore hypothesized that the transcriptional induction of the antisense MUTs during the onset of meiotic M-phase interferes with sense mRNA transcription, which may negatively regulate these proteins. Our tiling array data are in agreement with this notion [36]; (see sgv.genouest.org). To further explore this idea, we used strand-specific RNA/ribosome profiling data covering mitotic growth and meiotic development [28]. Indeed, the accumulation of MUT214 and MUT1155 correlates with strongly decreased mRNA levels and, as a consequence, ribosome footprints for SED4 and YMRO34C during meiotic M-phase (Figure 7B). These patterns are consistent with meiotic antisense interference, and may at least in part explain the decreasing protein levels observed for Sed4 and Ymr034c in differentiating cells.

\section{In vivo dsRNA formation is associated with fluctuating protein levels}

Among 17 mRNA/lncRNA pairs that can form dsRNAs in vivo during vegetative growth, we find 14 cases were lncRNA expression is associated with strongly fluctuating protein levels (in the most extreme cases no protein was detected in at least one sample). For MGR1/SUT1053 and PRY1/SUT209 (also annotated as XUT0531 [38]) no proteins are detected when lncRNAs accumulate and dsRNAs form in vegetatively growing cells (Figure 7A and C) and during late meiotic M-phase (SPII 8h; Figure S4; the full dataset will be published elsewhere). No effect of lncRNA expression and dsRNA formation was observed for HSP42/MUT276, SIS1/SUT2384, and TEF4/SUT1895 which might be due to an excess of mRNA versus lncRNA concentrations in the cell (Figure 7A).

Taken together, the data are consistent with the idea that induction of meiotic antisense lncRNAs (i) can be correlated with decreased overlapping sense mRNA (hence protein) levels, which is likely due to transcription interference, and (ii) can lead to the formation of putative regulatory dsRNAs that may influence protein levels. 


\section{Discussion}

The present study provides initial quantitative insight into the dynamic proteome underlying the switch from mitosis to meiosis, the latter of which is a key step of gametogenesis in the simple eukaryote $S$. cerevisiae. We integrated large-scale protein-profiling data obtained via mass spectrometry with information from genome-wide and strand-specific RNA profiling studies based on tiling arrays and RNA-Sequencing. Our results (i) identify differentially expressed proteins showing correlated or uncoupled mRNA/protein profiles in mitosis and meiosis, (ii) suggest novel functions in meiosis and gametogenesis for poorly characterized proteins, and (iii) associate protein levels with developmental stage-specific antisense lncRNA expression via transcriptional interference and dsRNA formation.

\section{Correlating mRNA/protein peak levels and essential function in meiosis}

When transcriptome and proteome data from vegetatively growing cells were combined, it was critically noted that mRNA and protein levels often did not correspond to each other; this phenomenon was reported to also occur in meiosis in later work [4, 20, 23]. We do, however, not think that this is a problem - quite the opposite. Uncoupled mRNA/protein patterns are interesting, because they typically point to novel mechanisms for translational control via, for example, extended 5'- or 3'-UTRs that inhibit or enhance ribosome activities, or dsRNAs that trigger selective degradation of mRNAs [28, 37]. Moreover, the small but critical group of yeast genes, which are genuinely specific and essential for gametogenesis, actually does show tightly correlated mRNA/protein patterns that typically peak at the developmental stage where the protein acts (see Figures 4 and 5; [3, 9]; for review, see [97]). For such cases, transcriptional induction and function in meiosis are statistically significantly correlated [15].

We note that the present analysis failed to detect some early meiotic proteins, which are expressed at very low levels because they typically fulfil enzymatic functions important for processes such as recombination, chromosome synapsis and chromosome separation [98, 99]. However, our study provided, among many others, robust quantitative profiling data for more abundant meiotic enzymes (e.g. Dmc1, Ime2, Smk1), transcription factors (Msa2, Swi6), a factor involved in chromosome separation (Spo21), and proteins important for gamete formation and maturation (Bem2, Dtr1, Gas2, Lds1, Loh1, Spo19, Sps2, Sps22, Tep1). In summary, we conclude that quantitative insight into the meiotic proteome helps complete our understanding of the expression program underlying gametogenesis, and facilitates the 
discovery of novel functions for protein-coding genes that are directly or indirectly required for optimal cell differentiation.

\section{The role of IncRNAs in controlling the proteome}

Determining global protein concentrations during growth and development identifies many stage-specific proteins, and others that show large differences in their steady-state levels. This raises the question how such patterns arise. Classical views include coupled mRNA/protein expression whereby timing of induction and time of translation (hence function) overlap [97, 100]. More recently it was proposed that transcript isoforms with extended 5'-UTRs contribute to controlling protein levels during sporulation [28, 29, 35, 101].

How might lncRNAs control protein expression in meiotic cells? While two studies have addressed the function of lncRNAs in coordinating entry into budding yeast meiosis, their roles during the process remain a matter of speculation [94, 102]. In the distantly related fission yeast Schizosaccharomyces pombe, lncRNAs have also been found to regulate entry into meiosis, albeit using different mechanisms; for review see [103, 104]. Critically, in $S$. pombe a non-coding RNA was not only shown to regulate the onset of cell differentiation, but to be involved in a key meiotic step - chromosome synapsis - itself [105]. In the current study we provide initial evidence that antisense interference, a process whereby the expression of sense mRNAs is inhibited by the induction of overlapping antisense lncRNAs, appears to act not only at the onset of meiosis but also during the process (MUT214, MUT1155, see Figure 7B) [94].

When interpreting data on lncRNAs it might be helpful not to simply apply working hypotheses known to fit mRNAs. That is, unlike mRNAs that typically have the unique role of encoding (multiple isoforms of) proteins, an lncRNA may have evolved to fulfil several roles at once. For example, MUT214's and MUT1155's synthesis may interfere with the expression of SED4 and YMRO34C and, when the lncRNAs are in the cytoplasm, they may attenuate together with (numerous) other lncRNAs protein translation during sporulation by engaging ribosomes in non-productive interactions (see Figure 7B and for example MUT1465 in [28]). While this idea is consistent with antagonistic mRNA/lncRNA patterns and ribosome footprints being limited to the extreme 5'-regions of MUT214 and MUT1155, we currently cannot exclude that these IncRNAs encode biologically active peptides. 
It has recently emerged that numerous overlapping pairs of sense/antisense transcripts involving mRNAs, IncRNAs or both can form dsRNAs in vivo [37, 95, 96]. It is unclear why some sense/antisense pairs do not appear to form such structures but this may be related to threshold levels of detection, or strain- and condition-dependent dsRNA stability. In any case, for yeast mRNA/mRNA dsRNAs it was shown that selective degradation of one participating mRNA via the so-called no go decay (triggered by stalled ribosomes), depletes cells of the corresponding protein [37]. In this context, it is intriguing that we find signal patterns consistent with a role for dsRNAs in down-regulating proteins during meiosis. For example, in the case of PRY1/SUT209 (XUT0531) [38] dsRNA is formed, and sense/antisense transcript concentrations are at a peak during mitosis when Pry 1 is undetectable by mass spectrometry. Pry1 belongs to a family of sterol-binding proteins that may play a role in metabolic processes involving prospore membrane formation during meiosis and sporulation [17, 106, 107]. It is not clear why Pry1 is present only at the onset of meiotic M-phase. However, the pattern we detect is consistent with work published 40 years ago showing that cerulenin, an inhibitor of fatty acid and sterol synthesis, could interfere with sporulation only during early but not late stages [108]. The tight post-transcriptional regulation of Pry1 is coherent with the fact that the phenomenon of dynamic changes in membrane lipid composition are conserved between yeast sporulation and mammalian spermatogenesis [109].

We also observed cases where dsRNA does not appear to strongly influence protein levels, which might mean that the sense/antisense transcripts form fortuitous structures that have no biological function. It could, however, also be that these proteins are unusually stable, thereby masking a negative effect of dsRNAs on translation. Alternatively, dsRNAs might retain transcripts in the nucleus, or protect mRNAs against degradation, thereby preserving them for rapid translation when spores germinate and newly formed cells undergo the first mitotic division.

\section{From large-scale protein profiling to the full meiotic proteome}

While the mitotic yeast proteome is well studied and methods have been developed to identify all known proteins in a growing cell undergoing rapid growth and divisions, only a limited number of proteins were identified in meiotic cells using 2D-gel technology. Using our approach, we identified all of 39 proteins listed in three relevant studies (Supplementary 
Table 3; [20-22]). This is not surprising since gel-based approaches tend to identify abundant proteins, which are usually very reliably detected by mass spectrometry. Furthermore, the output of meiotic proteins reported here is comparable to a recent protein-profiling analysis of yeast sporulation based on mass spectrometry (357 versus 381) [23]. However, we observe only a small overlap of 56 proteins that both studies detected (Figure S5A; Table S3). Since we used the same SK1 strain background as Wen et al. the large number of proteins identified in only one study is likely due to methodological differences in tryptic peptide fractionation prior to mass spectrometry analysis, resulting in comparatively low proteome coverage by our LTQ-OrbiTrap mass spectrometer in combination with the T3PQ quantification method [23].

While quantitative isotope labelling-based mass spectrometry approaches typically yield more proteins, the labelling step may introduce a technical bias into analyses of gametogenesis, because of substantial changes in cell metabolism and the chemistry of the cell wall that occur when cells progress through the meiotic differentiation pathway [17, 93]. We plan to address the critical issue of proteome coverage in future work by using an improved mass spectrometer such as triple-TOF, Q-OrbiTrap or Q-TOF in combination with a label-free method.

In this context is it perhaps noteworthy that among 357 proteins we quantified in at least one of the replicates from meiotic samples, 226 have human orthologs or homologs (Figure S5B; Table S4). Consistently, most of these human proteins have been detected in fetal and/or adult gonads in a recent mass-spectrometry based protein profiling experiment (www. humanproteomemap.org) [110]. Given that the human testis is key organ for ongoing work to complete the human proteome, further genomic and genetic studies will likely identify more conserved proteins potentially important for gametogenesis in yeast and mammals [111-113].

\section{Conclusion}

Previous studies and our work clearly indicate that protein extracts from sporulating cells are suitable for high-throughput studies in spite of elevated proteolytic activities and profound physiological and morphological changes that occur during the process. While considerable progress has been made in the field of reproductive genomics, much remains to be learned about the interplay between transcript isoforms, the sense/antisense transcriptomes, dsRNAs, and the proteome during gametogenesis. The stage is now set to combine the most advanced methods for RNA- and protein profiling of the meiotic developmental process in eukaryotes. 


\section{Acknowledgments}

We thank Mike Law for critical reading of the manuscript. We gratefully acknowledge Gloria Brar's help to set up RNA-Sequencing and ribosome profiling data in the Integrated Genomics Viewer (IGV). This work was in part funded by financial support provided to Michael Primig by Inserm (Avenir) and the University of Rennes 1.

\section{Figure legends}

Figure 1. Experimental design and total protein yield. (A) A schematic outlines the biological processes and the stages corresponding to cell samples. (B) A flow diagram summarizes the experimental approach. (C) Colour coded Venn diagrams show the numbers of proteins detected in duplicate samples cultured in rich medium with acetate (YPA, light orange) and in two time points in sporulation medium (SPII 6h and 8h, green). (D) A Venn diagram shows how many proteins were detected in only one condition or in multiple samples as indicated.

Figure 2. Differentially expressed proteins peaking in mitosis. (A) False colour heat maps are shown for protein levels (mass spectrometry) and RNA levels (tiling microarrays). Protein names are given to the left, the Cluster number (Cluster 1) is indicated to the right. Samples are shown at the top for proteins, protein-coding transcripts (sense mRNAs) and RNAs encoded on the opposite strand (antisense transcript). Scales for protein and RNA levels are given at the bottom. (B) A bar diagram shows enrichment (x-axis) of Gene Ontology terms (y-axis) for the cluster (percentage of annotated terms in light grey) versus the entire genome (in dark grey). The $p$-values, which were computed with a hypergeometrical law corrected for multiple testing (Benjamini and Hochberg), are indicated. (C-D) Data are shown for Cluster 2 like in panels A and B. Colour-coded arrows mark selected proteins exemplifying four different categories as indicated at the bottom.

Figure 3. Differentially expressed proteins peaking in meiosis I and II. (A-D) Protein data, RNA data and Gene Ontology enrichment values for Cluster 3 and Cluster 4 are shown as in Figure 2. (E-F). Protein data, RNA data and Gene Ontology enrichment values for cluster 5 are shown as in Figure 2. 
Figure 4. Specific proteins peaking in meiosis I. (A-D) Protein data, RNA data and Gene Ontology enrichment values for msClusters 1 and 2 are shown as in Figure 2.

Figure 5. Specific proteins peaking in meiosis II. (A-D) Protein data, RNA data and Gene Ontology enrichment values for msClusters 3 and 4 are shown as in Figure 2.

Figure 6. Chemoprofiling and sporulation. Protein and RNA profiling data are shown as in Figure 2. Colour-coded squares mark significant sensitivity of a mutant strain against selected therapeutic molecules grouped into five categories as given at the bottom; the complete dataset was reported by [16]. Green arrows indicate gene known to be important for meiosis and/or gametogenesis.

Figure 7. Association of protein levels with sense/antisense expression. (A) Protein and RNA profiling data are shown as in Figure 2. Transcript pairs that form double-stranded RNAs in vivo (dsRNA) are indicated by a dot. (B) Bar diagrams created with IGV are shown. Transcripts are given in blue (RNA profiles), ribosome interactions (ribosome footprints) are shown in red. Open reading frames are given in blue, lncRNAs are shown in yellow (MUTs) and red (XUT). Sample names are given to the left; data types are indicated to the right. The display parameters were bar chart, log scale, data range 0-200 for mRNA and 0-20 for ribosome footprints. (C) A histogram shows dsRNA profiling data for MGR1/SUT1053 and PRY1/SUT209 in wild type (WT) and mutant strains (xrn1) and corresponding strains expressing Dicer and Argonaut (RNAi and xrn1 RNAi). Log 2 tag intensities (x-axis) are plotted for each base (y-axis). Genome coordinates are shown. Signals corresponding to the top (+) and bottom (-) strands are given in blue and red, respectively. Genes are shown as violet rectangles, lncRNAs are given in red (XUT) and light blue (SUT). Arrows indicate the transcriptional direction.

Figure S1. Sample fractionation and distribution of protein abundance. (A) The image of a Coomassie-stained SDS gel resolving total protein extracts from mitotic duplicate samples (YPA 1 and 2), and meiotic samples (SPII 6h 1, 2 and SPII 8h 1,2) is shown. The last lane contains molecular weight markers (MW). Values in kilo Dalton $(\mathrm{kD})$ are given to the right. 
A schematic to the left represents 30 bands that were excised from each lane for further processing. (B) A colour coded boxplot shows the distributions of log2-transformed protein abundance signals (x-axis) in duplicate samples from cells grown in pre-sporulation medium (YPA) and sporulation medium (SPII) at the time points indicated (y-axis). A horizontal black line is the median. The boxes indicate the $1^{\text {st }}$ and $3^{\text {rd }}$ quantile, which reflects the interquartile range (IQR). Whiskers extend to $1.5 \mathrm{x} \mathrm{IQR}$ from the box. (C) A composite diagram shows the number of proteins detected in each of the sample duplicates from mitotic cells (YPA 1 and 2) and meiotic cells (SPII6h 1 and 2, SPII8h 1 and 2). Dots represent 40 protein quantification patterns in the complete sample set (x-axis), and a bar diagram above the dots shows the number of proteins for each pattern (y-axis).

Figure S2. Experimental approach for the identification of fluctuating proteins. A flow chart outlines the method used to identify proteins showing variable signal intensities.

Figure S3. Experimental approach for the identification of SPII-specific proteins. A flow chart outlines the method used to identify proteins detected only in sporulation medium (SPII).

Figure S4. dsRNA profiling in mitosis and meiosis. Histograms shows dsRNA profiling data for MGR1/SUT1053 and PRY1/SUT209 in wild type (WT) and Dicer/Argonaut (DA) cultured in rich medium (YPD) or sporulation medium (SPII 8h) as indicated. Log 2 tag intensities (x-axis) are plotted for each base (y-axis). Genome coordinates are shown. Signals corresponding to the top (+) and bottom (-) strands are given in blue and red, respectively. Genes and dubious open reading frames are shown as dark blue and while rectangles, respectively, lncRNAs are given in red (XUT), light blue (SUT), magenta (CUT), and yellow (MUT). Arrows indicate the transcriptional direction.

Figure S5. Comparison of protein profiling output. A Venn diagram comparing the proteins identified by reference [23] (Wen et al.) to our results (this study) is shown. 


\section{Tables}

Table 1. Total numbers of proteins identified in each sample.

\begin{tabular}{|l|l|}
\hline Sample & $\mathbf{N}^{\mathbf{0}}$ of proteins identified \\
\hline YPA 1 & 1644 \\
\hline YPA 2 & 1443 \\
\hline SPII6h 1 & 1322 \\
\hline SPII6h 2 & 1160 \\
\hline SPII8h 1 & 1199 \\
\hline SPII8h 2 & 844 \\
\hline Total non-redundant hits & 2366 \\
\hline
\end{tabular}

Table S1. Global data integration. This file contains protein profiling data (tab1; not quantified (NQ) signifies that the protein was detected but it was not possible to reliably quantify it, not available (NA) signifies that the protein was not detected), integrated protein-, RNA-, and chemoprofiling data (tab2), and data for selected meiosis-specific genes for which no molecular function is annotated (tab3).

Table S2. Sense/antisense expression. This file contains gene-, and lncRNA annotation, protein profiling data, and sense/antisense expression data.

Table S3. Protein profiling overlap. This file contains the names of proteins shown in Figure S4a.

Table S4. Protein profiling overlap. This file contains the names of proteins shown in Figure S4b. 


\section{References}

[1] Liti G, Carter DM, Moses AM, Warringer J, Parts L, James SA, et al. Population genomics of domestic and wild yeasts. Nature. 2009;458:337-41.

[2] Cho RJ, Campbell MJ, Winzeler EA, Steinmetz L, Conway A, Wodicka L, et al. A genome-wide transcriptional analysis of the mitotic cell cycle. Mol Cell. 1998;2:65-73.

[3] Chu S, DeRisi J, Eisen M, Mulholland J, Botstein D, Brown PO, et al. The transcriptional program of sporulation in budding yeast. Science. 1998;282:699-705.

[4] de Godoy LM, Olsen JV, Cox J, Nielsen ML, Hubner NC, Frohlich F, et al. Comprehensive mass-spectrometry-based proteome quantification of haploid versus diploid yeast. Nature. 2008;455:1251-4.

[5] Geijer C, Pirkov I, Vongsangnak W, Ericsson A, Nielsen J, Krantz M, et al. Time course gene expression profiling of yeast spore germination reveals a network of transcription factors orchestrating the global response. BMC Genomics. 2012;13:554.

[6] Granovskaia MV, Jensen LJ, Ritchie ME, Toedling J, Ning Y, Bork P, et al. Highresolution transcription atlas of the mitotic cell cycle in budding yeast. Genome Biol. 2010;11:R24.

[7] Nagalakshmi U, Wang Z, Waern K, Shou C, Raha D, Gerstein M, et al. The transcriptional landscape of the yeast genome defined by RNA sequencing. Science. 2008;320:1344-9.

[8] Picotti P, Bodenmiller B, Mueller LN, Domon B, Aebersold R. Full dynamic range proteome analysis of S. cerevisiae by targeted proteomics. Cell. 2009;138:795-806.

[9] Primig M, Williams RM, Winzeler EA, Tevzadze GG, Conway AR, Hwang SY, et al. The core meiotic transcriptome in budding yeasts. Nat Genet. 2000;26:415-23.

[10] Lavigne R, Becker E, Liu Y, Evrard B, Lardenois A, Primig M, et al. Direct iterative protein profiling (DIPP) - an innovative method for large-scale protein detection applied to budding yeast mitosis. Molecular \& cellular proteomics : MCP. 2012;11:M111 012682.

[11] Becker E, Liu Y, Lardenois A, Walther T, Horecka J, Stuparevic I, et al. Integrated RNA- and protein profiling of fermentation and respiration in diploid budding yeast provides insight into nutrient control of cell growth and development. Journal of proteomics. 2015;119:30-44.

[12] Lee AY, St Onge RP, Proctor MJ, Wallace IM, Nile AH, Spagnuolo PA, et al. Mapping the cellular response to small molecules using chemogenomic fitness signatures. Science. 2014;344:208-11.

[13] Winzeler EA, Shoemaker DD, Astromoff A, Liang H, Anderson K, Andre B, et al. Functional characterization of the S. cerevisiae genome by gene deletion and parallel analysis. Science. 1999;285:901-6.

[14] Enyenihi AH, Saunders WS. Large-scale functional genomic analysis of sporulation and meiosis in Saccharomyces cerevisiae. Genetics. 2003;163:47-54.

[15] Deutschbauer AM, Williams RM, Chu AM, Davis RW. Parallel phenotypic analysis of sporulation and postgermination growth in Saccharomyces cerevisiae. Proc Natl Acad Sci U S A. 2002;99:15530-5.

[16] Hillenmeyer ME, Fung E, Wildenhain J, Pierce SE, Hoon S, Lee W, et al. The chemical genomic portrait of yeast: uncovering a phenotype for all genes. Science. 2008;320:362-5.

[17] Neiman AM. Sporulation in the budding yeast Saccharomyces cerevisiae. Genetics. 2011;189:737-65.

[18] Zaman S, Lippman SI, Zhao X, Broach JR. How Saccharomyces Responds to Nutrients. Annu Rev Genet. 2008.

[19] Weidberg H, Moretto F, Spedale G, Amon A, van Werven FJ. Nutrient Control of Yeast Gametogenesis Is Mediated by TORC1, PKA and Energy Availability. PLoS genetics. 2016;12:e1006075. 
[20] Grassl J, Scaife C, Polden J, Daly CN, Iacovella MG, Dunn MJ, et al. Analysis of the budding yeast $\mathrm{pH}$ 4-7 proteome in meiosis. Proteomics. 2010;10:506-19.

[21] Kumar R, Dhali S, Srikanth R, Ghosh SK, Srivastava S. Comparative proteomics of mitosis and meiosis in Saccharomyces cerevisiae. Journal of proteomics. 2014;109:1-15.

[22] Scaife C, Mowlds P, Grassl J, Polden J, Daly CN, Wynne K, et al. 2-D DIGE analysis of the budding yeast $\mathrm{pH}$ 6-11 proteome in meiosis. Proteomics. 2010;10:4401-14.

[23] Wen FP, Guo YS, Hu Y, Liu WX, Wang Q, Wang YT, et al. Distinct temporal requirements for autophagy and the proteasome in yeast meiosis. Autophagy. 2016;12:67188.

[24] Berchowitz LE, Gajadhar AS, van Werven FJ, De Rosa AA, Samoylova ML, Brar GA, et al. A developmentally regulated translational control pathway establishes the meiotic chromosome segregation pattern. Genes Dev. 2013;27:2147-63.

[25] Zubenko GS, Jones EW. Protein degradation, meiosis and sporulation in proteinasedeficient mutants of Saccharomyces cerevisiae. Genetics. 1981;97:45-64.

[26] Klar AJ, Halvorson HO. Proteinase activities of Saccharomyces cerevisiae during sporulation. J Bacteriol. 1975;124:863-9.

[27] Berchowitz LE, Kabachinski G, Walker MR, Carlile TM, Gilbert WV, Schwartz TU, et al. Regulated Formation of an Amyloid-like Translational Repressor Governs Gametogenesis. Cell. 2015;163:406-18.

[28] Brar GA, Yassour M, Friedman N, Regev A, Ingolia NT, Weissman JS. High-resolution view of the yeast meiotic program revealed by ribosome profiling. Science. 2012;335:552-7.

[29] Lardenois A, Stuparevic I, Liu Y, Law MJ, Becker E, Smagulova F, et al. The conserved histone deacetylase Rpd3 and its DNA binding subunit Ume6 control dynamic transcript architecture during mitotic growth and meiotic development. Nucleic Acids Res. 2015;43:115-28.

[30] Neil H, Malabat C, d'Aubenton-Carafa Y, Xu Z, Steinmetz LM, Jacquier A. Widespread bidirectional promoters are the major source of cryptic transcripts in yeast. Nature. 2009;457:1038-42.

[31] Xu Z, Wei W, Gagneur J, Perocchi F, Clauder-Munster S, Camblong J, et al. Bidirectional promoters generate pervasive transcription in yeast. Nature. 2009;457:1033-7.

[32] Pelechano V, Steinmetz LM. Gene regulation by antisense transcription. Nat Rev Genet. 2013;14:880-93.

[33] Wei W, Pelechano V, Jarvelin AI, Steinmetz LM. Functional consequences of bidirectional promoters. Trends in genetics : TIG. 2011;27:267-76.

[34] Wery M, Kwapisz M, Morillon A. Noncoding RNAs in gene regulation. Wiley interdisciplinary reviews Systems biology and medicine. 2011;3:728-38.

[35] Kim Guisbert KS, Zhang Y, Flatow J, Hurtado S, Staley JP, Lin S, et al. Meiosis-induced alterations in transcript architecture and noncoding RNA expression in S. cerevisiae. RNA. 2012;18:1142-53.

[36] Lardenois A, Liu Y, Walther T, Chalmel F, Evrard B, Granovskaia M, et al. Execution of the meiotic noncoding RNA expression program and the onset of gametogenesis in yeast require the conserved exosome subunit Rrp6. Proc Natl Acad Sci U S A. 2011;108:1058-63.

[37] Sinturel F, Navickas A, Wery M, Descrimes M, Morillon A, Torchet C, et al. Cytoplasmic Control of Sense-Antisense mRNA Pairs. Cell reports. 2015;12:1853-64.

[38] Wery M, Descrimes M, Vogt N, Dallongeville AS, Gautheret D, Morillon A. NonsenseMediated Decay Restricts LncRNA Levels in Yeast Unless Blocked by Double-Stranded RNA Structure. Mol Cell. 2016.

[39] Selevsek N, Chang CY, Gillet LC, Navarro P, Bernhardt OM, Reiter L, et al. Reproducible and consistent quantification of the Saccharomyces cerevisiae proteome by SWATH-mass spectrometry. Molecular \& cellular proteomics : MCP. 2015;14:739-49. 
[40] Silva JC, Gorenstein MV, Li GZ, Vissers JP, Geromanos SJ. Absolute quantification of proteins by LCMSE: a virtue of parallel MS acquisition. Molecular \& cellular proteomics : MCP. 2006;5:144-56.

[41] Grossmann J, Roschitzki B, Panse C, Fortes C, Barkow-Oesterreicher S, Rutishauser D, et al. Implementation and evaluation of relative and absolute quantification in shotgun proteomics with label-free methods. Journal of proteomics. 2010;73:1740-6.

[42] Vizcaino JA, Deutsch EW, Wang R, Csordas A, Reisinger F, Rios D, et al. ProteomeXchange provides globally coordinated proteomics data submission and dissemination. Nat Biotechnol. 2014;32:223-6.

[43] R Development Core Team. R: A language and environment for statistical computing. R Foundation for Statistical Computing, Vienna, Austria; 2012.

[44] Smyth GK. Linear models and empirical bayes methods for assessing differential expression in microarray experiments. Stat Appl Genet Mol Biol. 2004;3:Article3.

[45] Maechler M, Rousseeuw P, Struyf A, Hubert M, Hornik K. cluster: Cluster Analysis Basics and Extensions. 2.0.3 ed2015. p. R package.

[46] Hartigan JA, Wong MA. A K-means clustering algorithm. Applied Statistics. 1979;28:100-8.

[47] Gene Ontology C. Gene Ontology Consortium: going forward. Nucleic Acids Res. 2015;43:D1049-56.

[48] Martin D, Brun C, Remy E, Mouren P, Thieffry D, Jacq B. GOToolBox: functional analysis of gene datasets based on Gene Ontology. Genome Biol. 2004;5:R101.

[49] Benjamini Y, Hochberg Y. Controlling the false discovery rate: a practical and powerful approach to multiple testing. . J R Statist Soc B 1995;57:289-300.

[50] Lardenois A, Gattiker A, Collin O, Chalmel F, Primig M. GermOnline 4.0 is a genomics gateway for germline development, meiosis and the mitotic cell cycle. Database : the journal of biological databases and curation. 2010;2010:baq030.

[51] Darde TA, Sallou O, Becker E, Evrard B, Monjeaud C, Le Bras Y, et al. The ReproGenomics Viewer: an integrative cross-species toolbox for the reproductive science community. Nucleic Acids Res. 2015;43:W109-16.

[52] Costanzo MC, Engel SR, Wong ED, Lloyd P, Karra K, Chan ET, et al. Saccharomyces genome database provides new regulation data. Nucleic Acids Res. 2014;42:D717-25.

[53] Coordinators NR. Database resources of the National Center for Biotechnology Information. Nucleic Acids Res. 2015.

[54] Thorvaldsdottir H, Robinson JT, Mesirov JP. Integrative Genomics Viewer (IGV): highperformance genomics data visualization and exploration. Briefings in bioinformatics. 2013;14:178-92.

[55] Mitchell SF, Jain S, She M, Parker R. Global analysis of yeast mRNPs. Nat Struct Mol Biol. 2013;20:127-33.

[56] Graille M, Baltaze JP, Leulliot N, Liger D, Quevillon-Cheruel S, van Tilbeurgh H. Structure-based functional annotation: yeast ymr099c codes for a D-hexose-6-phosphate mutarotase. J Biol Chem. 2006;281:30175-85.

[57] Friedman JR, Mourier A, Yamada J, McCaffery JM, Nunnari J. MICOS coordinates with respiratory complexes and lipids to establish mitochondrial inner membrane architecture. eLife. $2015 ; 4$.

[58] Vukotic M, Oeljeklaus S, Wiese S, Vogtle FN, Meisinger C, Meyer HE, et al. Rcf1 mediates cytochrome oxidase assembly and respirasome formation, revealing heterogeneity of the enzyme complex. Cell metabolism. 2012;15:336-47.

[59] von der Malsburg K, Muller JM, Bohnert M, Oeljeklaus S, Kwiatkowska P, Becker T, et al. Dual role of mitofilin in mitochondrial membrane organization and protein biogenesis. Developmental cell. 2011;21:694-707. 
[60] Ramaswamy NT, Li L, Khalil M, Cannon JF. Regulation of yeast glycogen metabolism and sporulation by Glc7p protein phosphatase. Genetics. 1998;149:57-72.

[61] Abdullah MF, Hoffmann ER, Cotton VE, Borts RH. A role for the MutL homologue MLH2 in controlling heteroduplex formation and in regulating between two different crossover pathways in budding yeast. Cytogenetic and genome research. 2004;107:180-90.

[62] Krogan NJ, Cagney G, Yu H, Zhong G, Guo X, Ignatchenko A, et al. Global landscape of protein complexes in the yeast Saccharomyces cerevisiae. Nature. 2006;440:637-43.

[63] Tevzadze GG, Swift H, Esposito RE. Spo1, a phospholipase B homolog, is required for spindle pole body duplication during meiosis in Saccharomyces cerevisiae. Chromosoma. 2000;109:72-85.

[64] Felder T, Bogengruber E, Tenreiro S, Ellinger A, Sa-Correia I, Briza P. Dtrlp, a multidrug resistance transporter of the major facilitator superfamily, plays an essential role in spore wall maturation in Saccharomyces cerevisiae. Eukaryotic cell. 2002;1:799-810.

[65] Ishihara S, Hirata A, Nogami S, Beauvais A, Latge JP, Ohya Y. Homologous subunits of 1,3-beta-glucan synthase are important for spore wall assembly in Saccharomyces cerevisiae. Eukaryotic cell. 2007;6:143-56.

[66] Irniger S. The Ime2 protein kinase family in fungi: more duties than just meiosis. Molecular microbiology. 2011;80:1-13.

[67] Heymont J, Berenfeld L, Collins J, Kaganovich A, Maynes B, Moulin A, et al. TEP1, the yeast homolog of the human tumor suppressor gene PTEN/MMAC1/TEP1, is linked to the phosphatidylinositol pathway and plays a role in the developmental process of sporulation. Proc Natl Acad Sci U S A. 2000;97:12672-7.

[68] Lin CP, Kim C, Smith SO, Neiman AM. A highly redundant gene network controls assembly of the outer spore wall in S. cerevisiae. PLoS genetics. 2013;9:e1003700.

[69] Sakaki K, Tashiro K, Kuhara S, Mihara K. Response of genes associated with mitochondrial function to mild heat stress in yeast Saccharomyces cerevisiae. Journal of biochemistry. 2003; 134:373-84.

[70] Christodoulidou A, Briza P, Ellinger A, Bouriotis V. Yeast ascospore wall assembly requires two chitin deacetylase isozymes. FEBS letters. 1999;460:275-9.

[71] Sansam CL, Pezza RJ. Connecting by breaking and repairing: mechanisms of DNA strand exchange in meiotic recombination. The FEBS journal. 2015;282:2444-57.

[72] Krisak L, Strich R, Winters RS, Hall JP, Mallory MJ, Kreitzer D, et al. SMK1, a developmentally regulated MAP kinase, is required for spore wall assembly in Saccharomyces cerevisiae. Genes Dev. 1994;8:2151-61.

[73] Bajgier BK, Malzone M, Nickas M, Neiman AM. SPO21 is required for meiosis-specific modification of the spindle pole body in yeast. Mol Biol Cell. 2001;12:1611-21.

[74] Tevzadze GG, Pierce JV, Esposito RE. Genetic evidence for a SPO1-dependent signaling pathway controlling meiotic progression in yeast. Genetics. 2007;175:1213-27.

[75] Ishihara M, Suda Y, Inoue I, Tanaka T, Takahashi T, Gao XD, et al. Protein phosphatase type 1-interacting protein Ysw1 is involved in proper septin organization and prospore membrane formation during sporulation. Eukaryotic cell. 2009;8:1027-37.

[76] Batisse J, Batisse C, Budd A, Bottcher B, Hurt E. Purification of nuclear poly(A)-binding protein Nab2 reveals association with the yeast transcriptome and a messenger ribonucleoprotein core structure. J Biol Chem. 2009;284:34911-7.

[77] Green DM, Marfatia KA, Crafton EB, Zhang X, Cheng X, Corbett AH. Nab2p is required for poly(A) RNA export in Saccharomyces cerevisiae and is regulated by arginine methylation via Hmt1p. J Biol Chem. 2002;277:7752-60.

[78] Cid VJ, Cenamor R, Sanchez M, Nombela C. A mutation in the Rho1-GAP-encoding gene BEM2 of Saccharomyces cerevisiae affects morphogenesis and cell wall functionality. Microbiology. 1998;144 ( Pt 1):25-36. 
[79] Grandin N, Reed SI. Differential function and expression of Saccharomyces cerevisiae B-type cyclins in mitosis and meiosis. Mol Cell Biol. 1993;13:2113-25.

[80] Tibbles KL, Sarkar S, Novak B, Arumugam P. CDK-dependent nuclear localization of B-cyclin Clb1 promotes FEAR activation during meiosis I in budding yeast. PloS one. 2013;8:e79001.

[81] Williamson MS, Game JC, Fogel S. Meiotic gene conversion mutants in Saccharomyces cerevisiae. I. Isolation and characterization of pms1-1 and pms1-2. Genetics. 1985;110:60946.

[82] Guo H, King MC. A quality control mechanism linking meiotic success to release of ascospores. PloS one. 2013;8:e82758.

[83] Ragni E, Coluccio A, Rolli E, Rodriguez-Pena JM, Colasante G, Arroyo J, et al. GAS2 and GAS4, a pair of developmentally regulated genes required for spore wall assembly in Saccharomyces cerevisiae. Eukaryotic cell. 2007;6:302-16.

[84] Hontz RD, Niederer RO, Johnson JM, Smith JS. Genetic identification of factors that modulate ribosomal DNA transcription in Saccharomyces cerevisiae. Genetics. 2009;182:105-19.

[85] Byrne KP, Wolfe KH. The Yeast Gene Order Browser: combining curated homology and syntenic context reveals gene fate in polyploid species. Genome Res. 2005;15:1456-61.

[86] Fares H, Goetsch L, Pringle JR. Identification of a developmentally regulated septin and involvement of the septins in spore formation in Saccharomyces cerevisiae. The Journal of cell biology. 1996;132:399-411.

[87] Muthukumar G, Suhng SH, Magee PT, Jewell RD, Primerano DA. The Saccharomyces cerevisiae SPR1 gene encodes a sporulation-specific exo-1,3-beta-glucanase which contributes to ascospore thermoresistance. J Bacteriol. 1993;175:386-94.

[88] Coluccio A, Bogengruber E, Conrad MN, Dresser ME, Briza P, Neiman AM. Morphogenetic pathway of spore wall assembly in Saccharomyces cerevisiae. Eukaryotic cell. 2004;3:1464-75.

[89] Ismail KS, Sakamoto $\mathrm{T}$, Hasunuma $\mathrm{T}$, Kondo A. Time-based comparative transcriptomics in engineered xylose-utilizing Saccharomyces cerevisiae identifies temperature-responsive genes during ethanol production. Journal of industrial microbiology \& biotechnology. 2013;40:1039-50.

[90] Denisenko O, Bomsztyk K. Yeast hnRNP K-like genes are involved in regulation of the telomeric position effect and telomere length. Mol Cell Biol. 2002;22:286-97.

[91] Paquin N, Menade M, Poirier G, Donato D, Drouet E, Chartrand P. Local activation of yeast ASH1 mRNA translation through phosphorylation of Khd1p by the casein kinase Yck1p. Mol Cell. 2007;26:795-809.

[92] Rabitsch KP, Toth A, Galova M, Schleiffer A, Schaffner G, Aigner E, et al. A screen for genes required for meiosis and spore formation based on whole-genome expression. Curr Biol. 2001;11:1001-9.

[93] Walther T, Letisse F, Peyriga L, Alkim C, Liu Y, Lardenois A, et al. Developmental stage dependent metabolic regulation during meiotic differentiation in budding yeast. BMC biology. 2014;12:60.

[94] Hongay CF, Grisafi PL, Galitski T, Fink GR. Antisense transcription controls cell fate in Saccharomyces cerevisiae. Cell. 2006;127:735-45.

[95] Lybecker M, Zimmermann B, Bilusic I, Tukhtubaeva N, Schroeder R. The doublestranded transcriptome of Escherichia coli. Proc Natl Acad Sci U S A. 2014;111:3134-9.

[96] Portal MM, Pavet V, Erb C, Gronemeyer H. Human cells contain natural doublestranded RNAs with potential regulatory functions. Nat Struct Mol Biol. 2015;22:89-97.

[97] Kassir Y, Adir N, Boger-Nadjar E, Raviv NG, Rubin-Bejerano I, Sagee S, et al. Transcriptional regulation of meiosis in budding yeast. Int Rev Cytol. 2003;224:111-71. 
[98] Surosky RT, Esposito RE. Early meiotic transcripts are highly unstable in Saccharomyces cerevisiae. Mol Cell Biol. 1992;12:3948-58.

[99] Surosky RT, Strich R, Esposito RE. The yeast UME5 gene regulates the stability of meiotic mRNAs in response to glucose. Mol Cell Biol. 1994;14:3446-58.

[100] Mitchell AP. Control of meiotic gene expression in Saccharomyces cerevisiae. Microbiol Rev. 1994;58:56-70.

[101] Jin L, Zhang K, Xu Y, Sternglanz R, Neiman AM. Sequestration of mRNAs Modulates the Timing of Translation during Meiosis in Budding Yeast. Mol Cell Biol. 2015;35:3448-58.

[102] van Werven FJ, Neuert G, Hendrick N, Lardenois A, Buratowski S, van Oudenaarden A, et al. Transcription of two long noncoding RNAs mediates mating-type control of gametogenesis in budding yeast. Cell. 2012;150:1170-81.

[103] Yamashita A, Shichino Y, Yamamoto M. The long non-coding RNA world in yeasts. Biochimica et biophysica acta. 2015.

[104] Hiriart E, Verdel A. Long noncoding RNA-based chromatin control of germ cell differentiation: a yeast perspective. Chromosome research : an international journal on the molecular, supramolecular and evolutionary aspects of chromosome biology. 2013;21:653-63. [105] Ding DQ, Okamasa K, Yamane M, Tsutsumi C, Haraguchi T, Yamamoto M, et al. Meiosis-specific noncoding RNA mediates robust pairing of homologous chromosomes in meiosis. Science. 2012;336:732-6.

[106] Deng L, Nagasawa J, Ono Y, Ishikawa Y, Kakihara T, Fukuda R, et al. Manipulation of major membrane lipid synthesis and its effects on sporulation in Saccharomyces cerevisiae. Biosci Biotechnol Biochem. 2008;72:2362-8.

[107] Choudhary V, Schneiter R. Pathogen-Related Yeast (PRY) proteins and members of the CAP superfamily are secreted sterol-binding proteins. Proc Natl Acad Sci U S A. 2012;109:16882-7.

[108] Ohno T, Awaya J, Omura S. Inhibition of sporulation by cerulenin and its reversion by exogenous fatty acids in Saccharomyces cerevisiae. Antimicrob Agents Chemother. 1976;9:42-8.

[109] Keber R, Rozman D, Horvat S. Sterols in spermatogenesis and sperm maturation. J Lipid Res. 2013;54:20-33.

[110] Kim MS, Pinto SM, Getnet D, Nirujogi RS, Manda SS, Chaerkady R, et al. A draft map of the human proteome. Nature. 2014;509:575-81.

[111] Djureinovic D, Fagerberg L, Hallstrom B, Danielsson A, Lindskog C, Uhlen M, et al. The human testis-specific proteome defined by transcriptomics and antibody-based profiling. Mol Hum Reprod. 2014;20:476-88.

[112] Jumeau F, Com E, Lane L, Duek P, Lagarrigue M, Lavigne R, et al. Human Spermatozoa as a Model for Detecting Missing Proteins in the Context of the ChromosomeCentric Human Proteome Project. Journal of proteome research. 2015;14:3606-20.

[113] Chocu S, Evrard B, Lavigne R, Rolland AD, Aubry F, Jegou B, et al. Forty-four novel protein-coding loci discovered using a proteomics informed by transcriptomics (PIT) approach in rat male germ cells. Biol Reprod. 2014;91:123. 

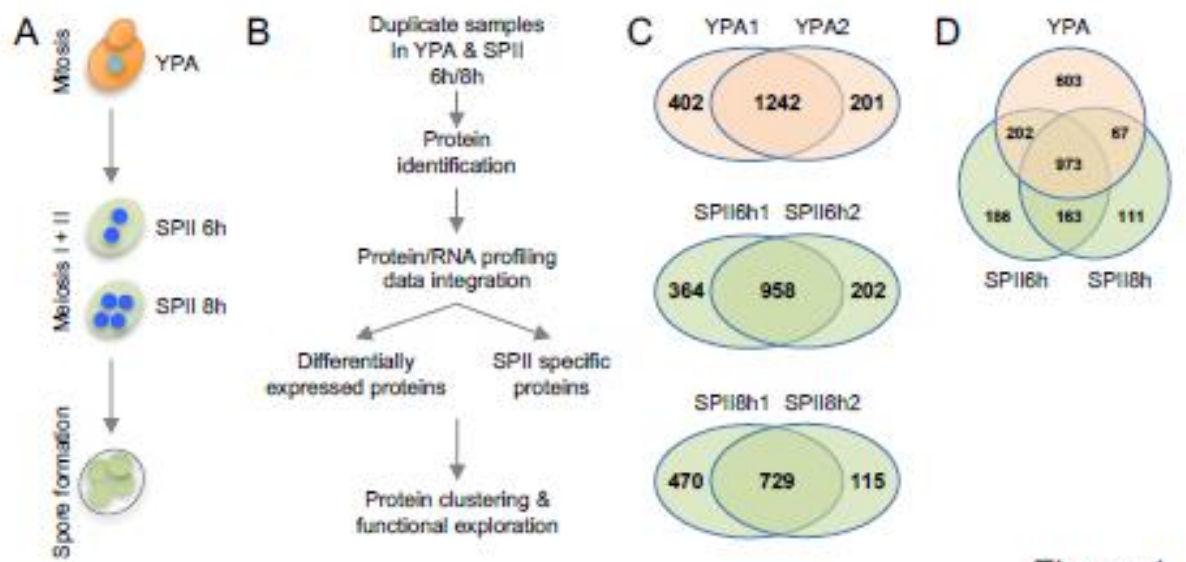

Figure 1 


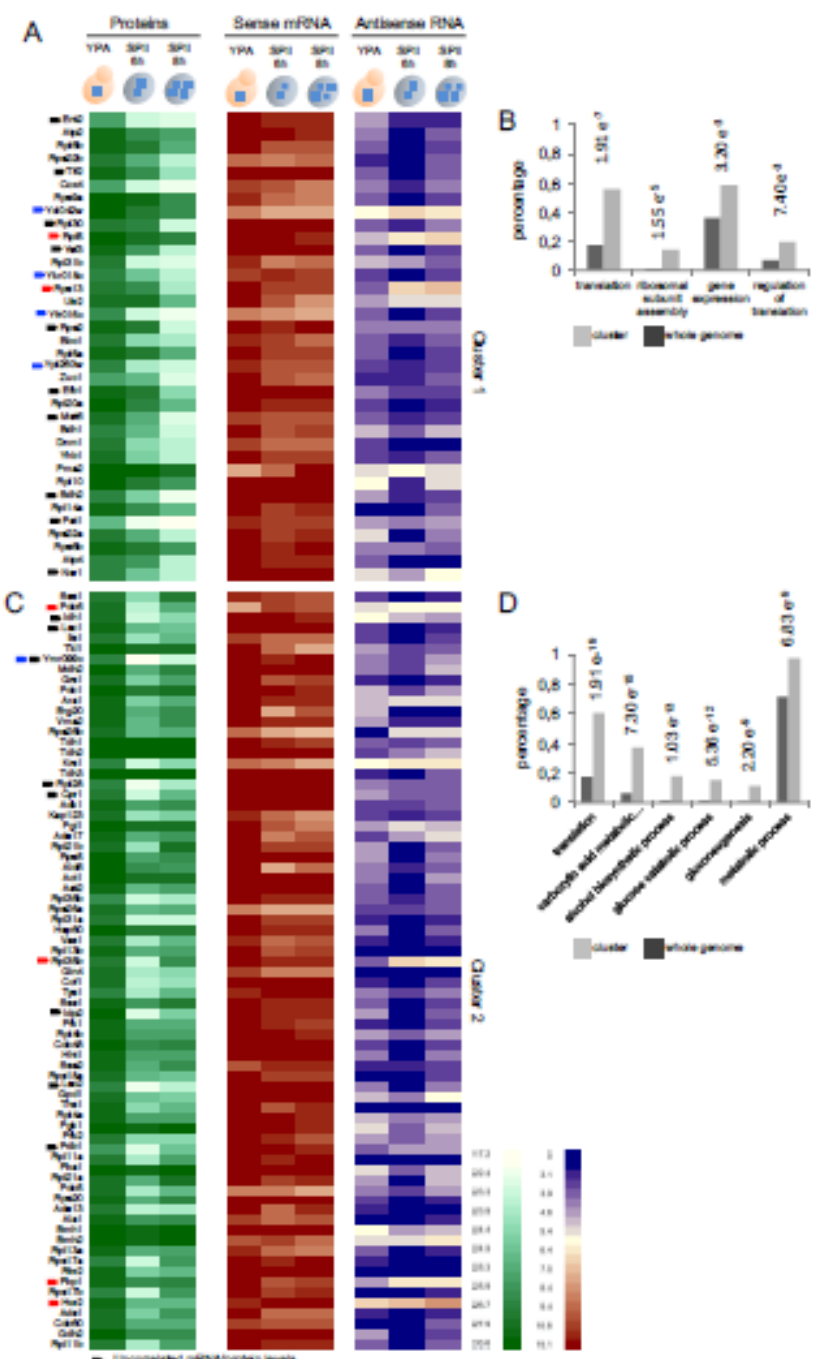




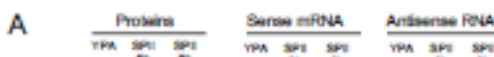

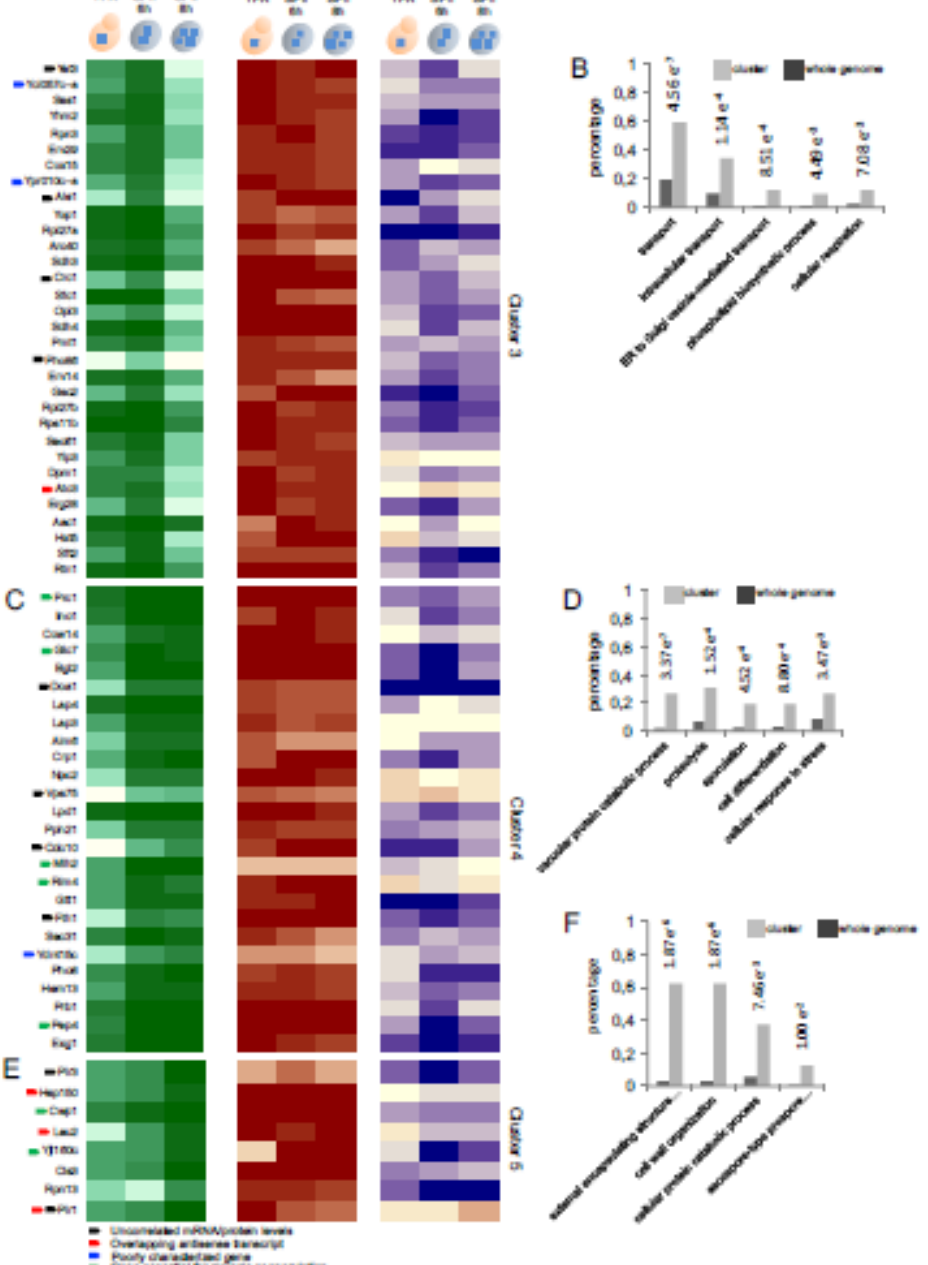

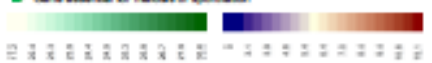

Figure 3 


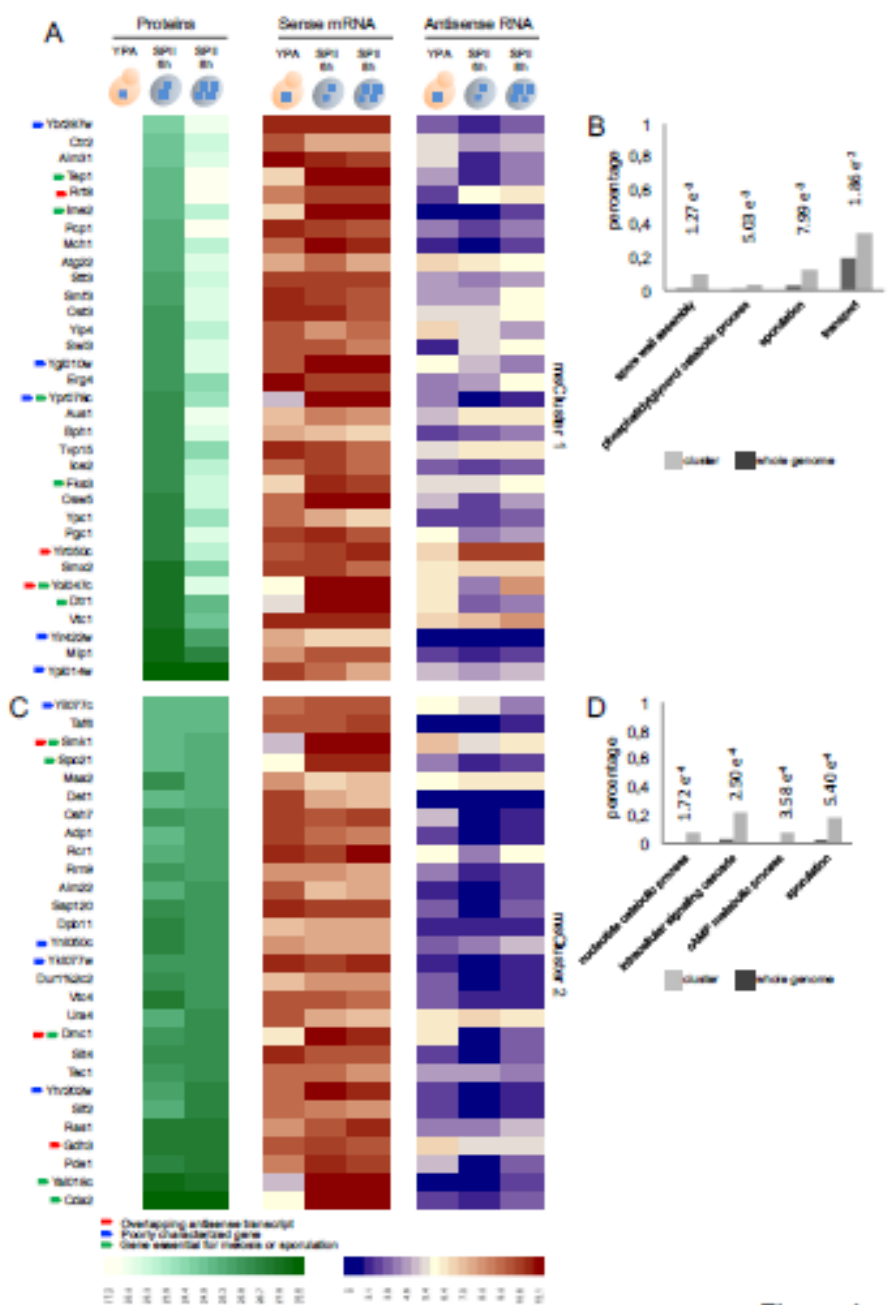

Figure 4 


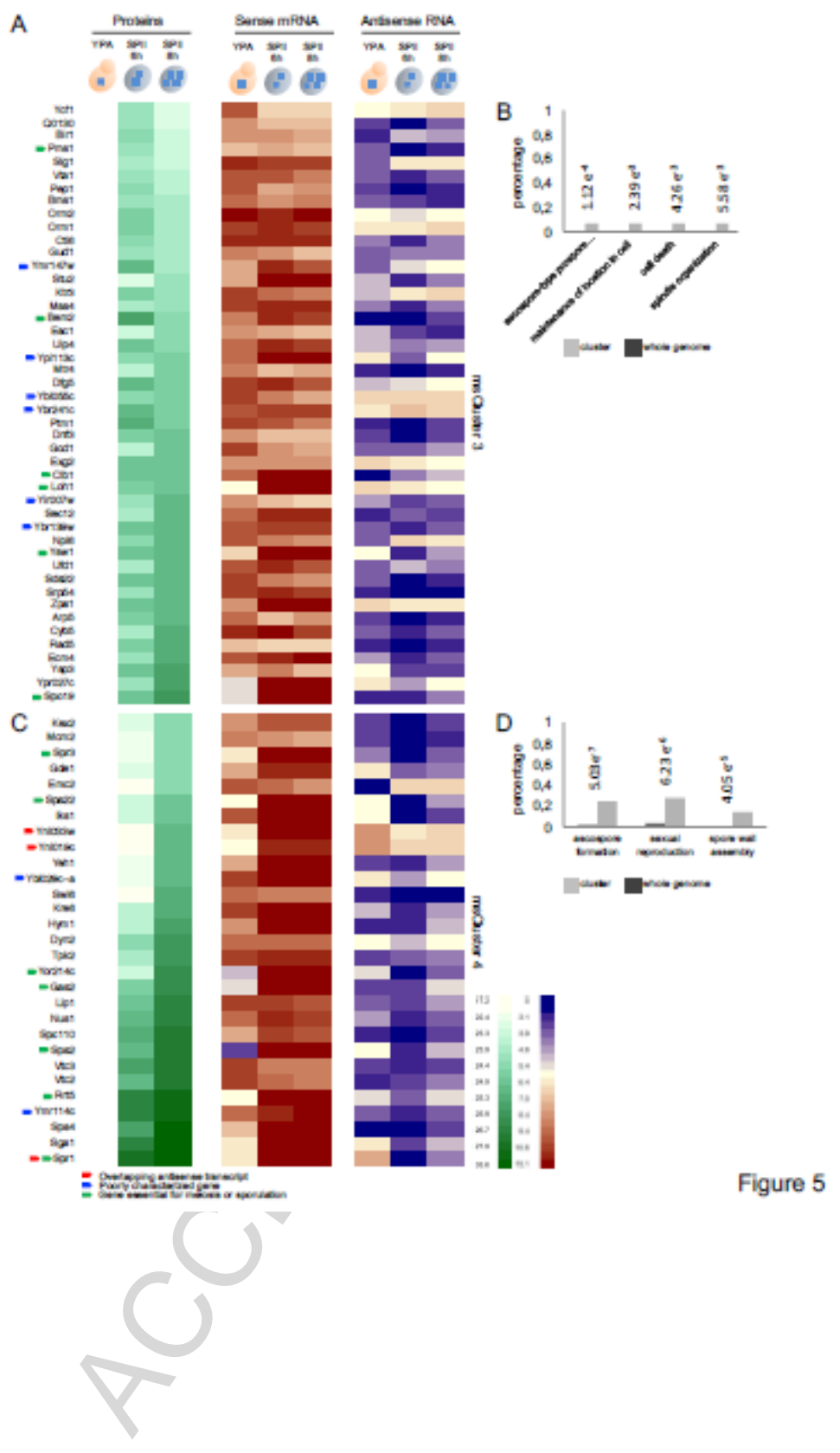




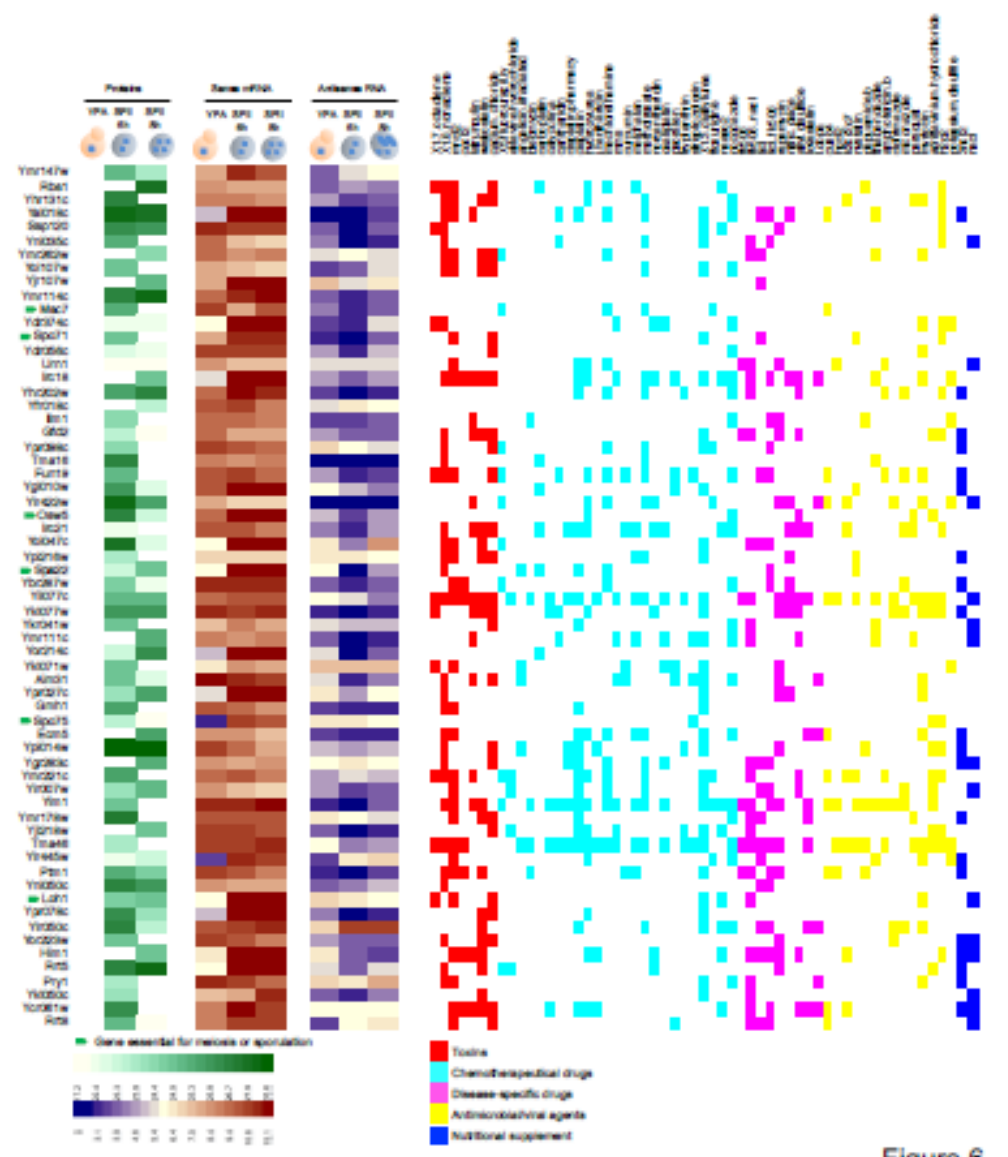

Figure 6 


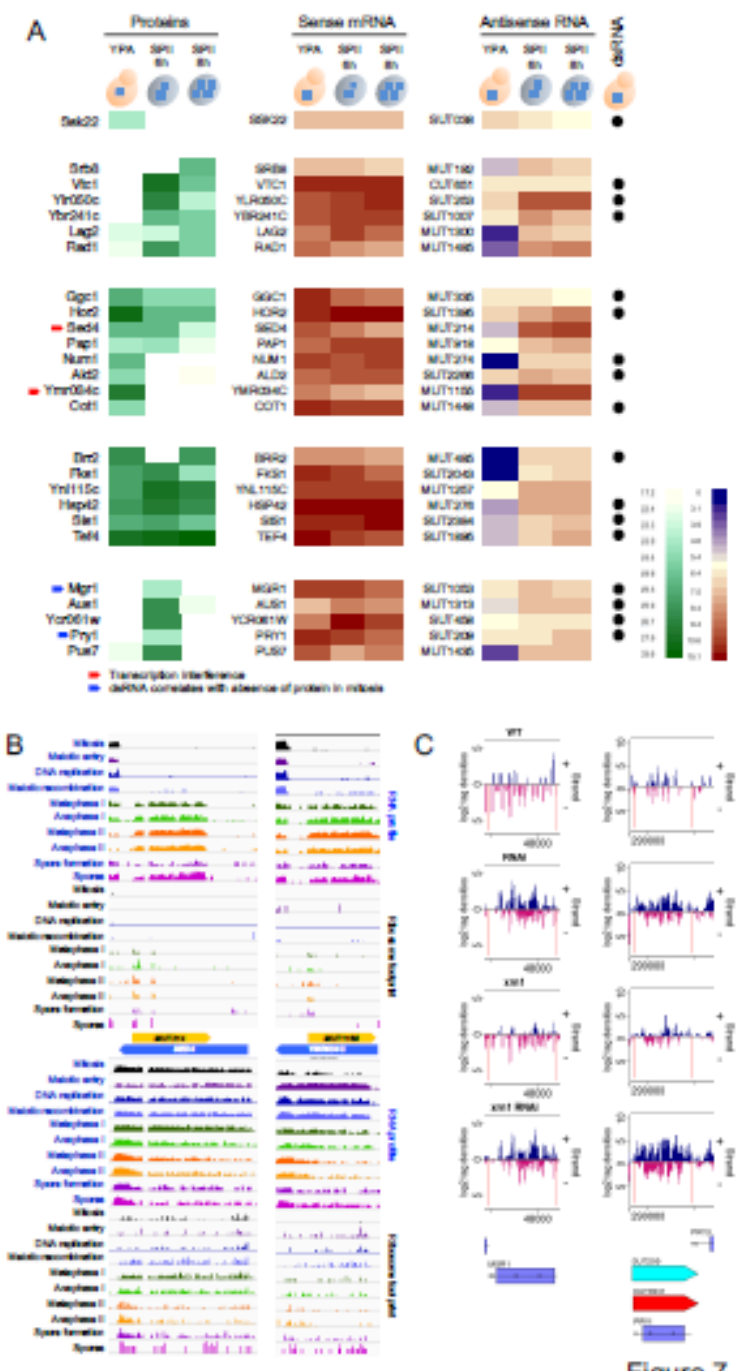

Figure 7 
Conflict of interest

The author declare no conflict of interest.

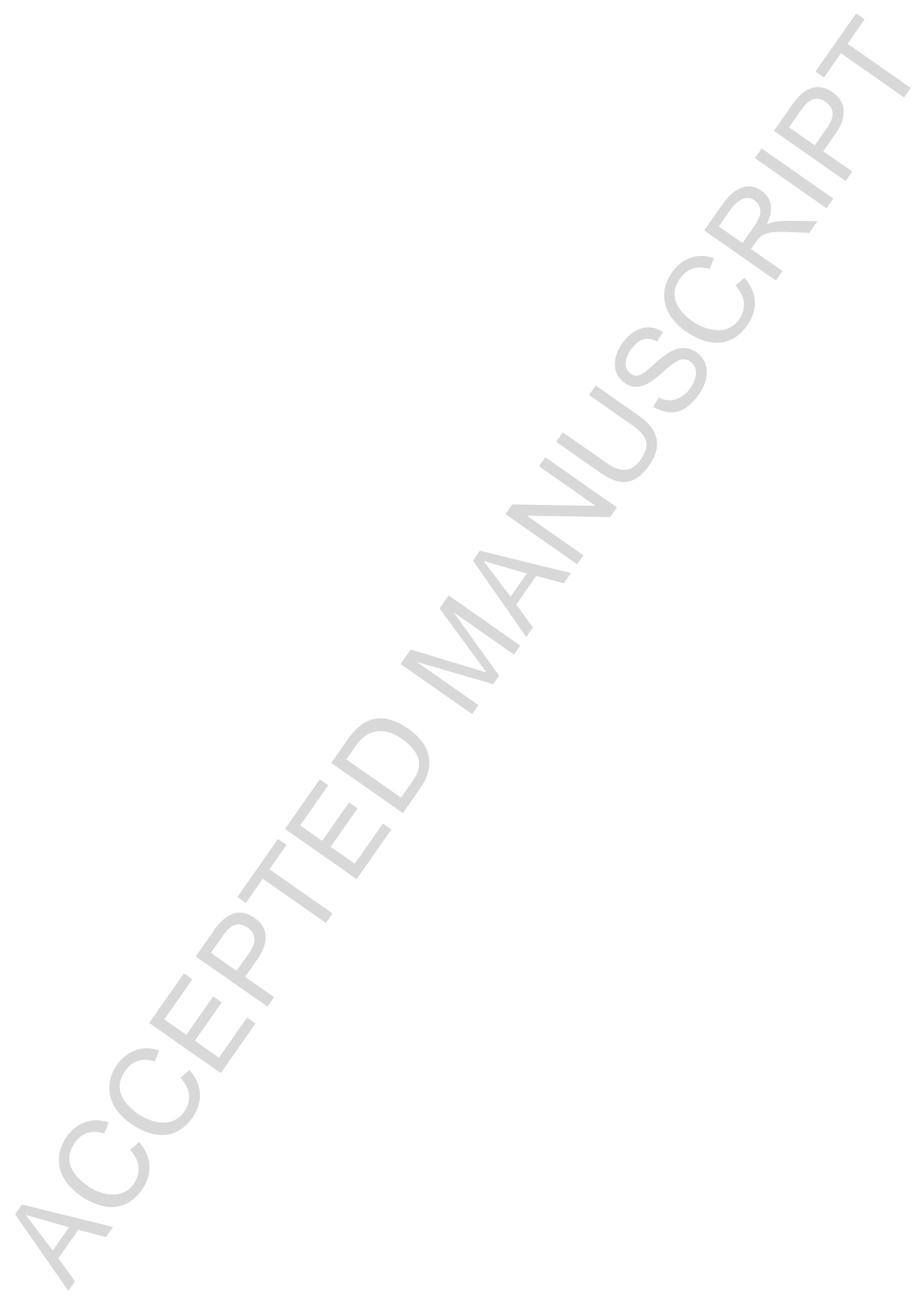


Graphical abstract
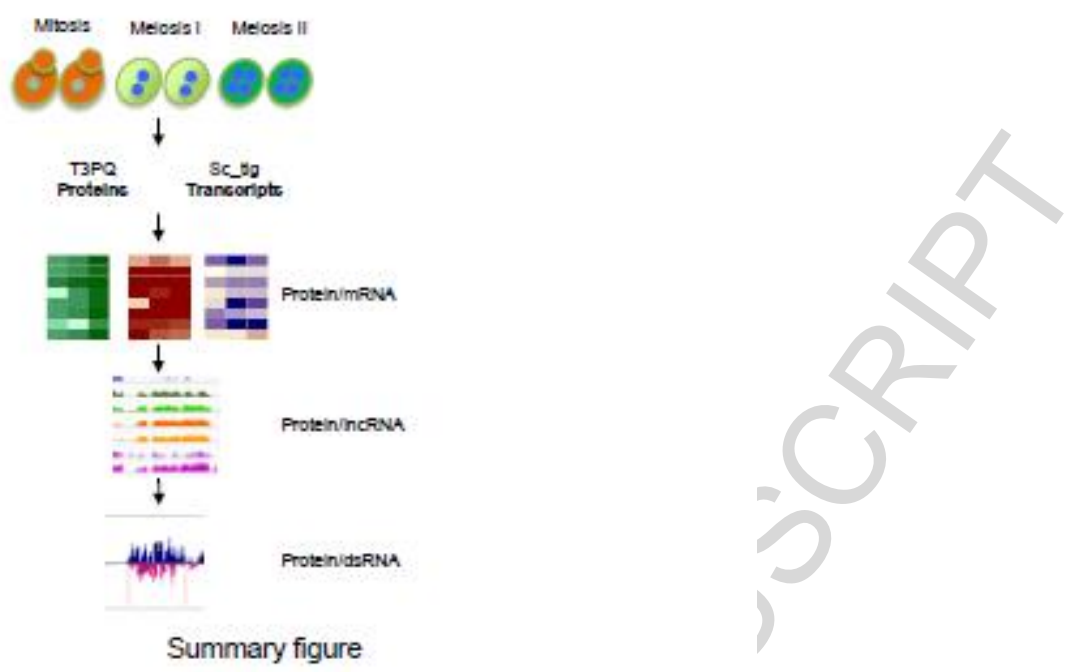